\title{
"The Reports of My Death Are Greatly Exaggerated"': Reading and Writing Objective Legal Memoranda in a Mobile Computing Age
}

Introduction 472

I. The Rhetorical Situation for the Legal Memorandum

A. Handling the "Imperfection": Lawyers (Still) Have a Duty to Give Competent Advice

B. Reading and Writing: Electronic Technology Impacts the Situation................................................................... 479

C. It's Tough Being a Lawyer............................................... 481

D. "Substantive" E-mail and the Death of the Traditional Memo.

\footnotetext{
* Professor of Law, Director of Legal Research and Writing, Stetson University College of Law, St. Petersburg, Florida. Ph.D, Arizona State University, Hugh Downs School of Human Communication; J.D., The Ohio State University Moritz College of Law; B.A., The Ohio State University. The author thanks Lauren Orebaugh and Lindsey Copeland for their research assistance on this article; Stetson University College of Law for supporting completion of this article with a research grant; Professors Linda Berger, Charles Calleros, Kristen Tiscione, and Jeff Todd for their helpful comments on earlier versions of this article; and Chris and Casey Reich, for being experts at mobile communication. An earlier version of this article was presented in a talk at Mercer University School of Law, Macon, GA; it is also the foundation for a presentation given at the 2013 Association of Legal Writing Directors Biennial Conference at Marquette University Law School, Milwaukee Wisconsin, entitled "Everything Old is New Again, Maybe: How Should Programs Teach the Interoffice Predictive Memo?" (with Charles Calleros and Kristen Tiscione).

1 Attributed to Samuel Longhorne Clemens (Mark Twain), appearing in a cable he sent from London to the United States press upon the erroneous publication of his obituary. See The American Heritage NeW Dictionary of Cultural Literacy (3d ed. 2005), available at http://dictionary.reference.com/browse/the+reports + of + my + death + are + greatly+exaggerated.
} 
II. Everything Old Is New Again: The Dangers of Killing

Off the Traditional Memo.

A. "Shorter" and "Easier" Is Not Necessarily Better: Competent, Deliberative Decision Making Through

Writing.

1. Lawyers and the Advice-Giving Function: The Duty to Doubt

2. The Meaning of Objectivity

3. Problems with Decision Making

4. Traditional Solutions to Modern Cognition Problems: The History of the Legal Memo

5. Writing, Structure, and Competent Advice Giving .... 502

B. "On-Screen" Is Not a New Legal Memo Category...

C. Inviting Legal Readers to "Stare" at the Screen:

Traditional Organizational Strategies and On-Screen

Reading

1. Reading on the Screen ............................................... 511

2. Text Structure and the Objective Memo................... 515

a. Overview of Text Structures ............................... 515

b. Text Structures and the Objective Memo ........... 517

c. Effective Text Structures for On-Screen

Reading

Conclusion

\section{INTRODUCTION}

Seventy years ago, carefully written objective legal memos ${ }^{2}-$ internal memoranda written by one lawyer to another for the purpose of communicating law and legal analysis and meant to serve as the basis for legal advice ${ }^{3}$ - were viewed as a critical part of

2 Objective legal memos are often alternatively referred to as predictive memos, internal memos, or office memos. See, e.g., ElizABETH FAJANS ET AL., Writing FOR LAW PRACTICE 271-72 (2d ed. 2010) (generally discussing the office memo). Their typical purpose is to analyze a legal issue, offer a prediction on the outcome of the issue, and either offer or provide the basis for advice based upon that analysis and prediction. See, e.g., id. Certainly, the objective memo writer is not purely objective; rather, he writes the memo thinking about "the best case for the client [considering the] arguments that plausibly can be made for the client." Id. at 271. The moniker "objective" as used here, however, is meant to distinguish a lawyer's goal of fairly assessing the possible arguments and predicting the outcomes in a legal matter as opposed to arguing one perspective on those outcomes. Id. at 304.

3 This definition of objective legal memorandum is the author's own but is based upon similar definitions by other writers. Id. at 271-72. 
practice. ${ }^{4}$ In today's legal practice culture of on-screen reading and writing, ${ }^{5}$ lawyers complain memos are expensive, time consuming, ${ }^{6}$ and perhaps even ill-suited for reading on screens and mobile devices. ${ }^{7}$ Memos can be seen as a waste of client resources, ${ }^{8}$ in part because of the inability of lawyers, particularly new lawyers who typically write memos, to write them well. ${ }^{9}$ Some scholars have suggested that new technology, such as e-mail, requires identifying a new category of legal writing described as "e-mail" or "informal" memos. ${ }^{10}$ As a result, scholars writing on the topic have called for an "update" to the "traditional" legal memo to make it more suited for the economic realities of practice and the technology on which memos are read. ${ }^{11}$ Some, in addition, suggest that we may want to kill

4 See, e.g., F. Trowbridge vom Baur, How to Look Up Law and Write Legal Memoranda, PRAC. LAW., Dec. 1956, at 27-28 (noting that the memorandum of law is a "fundamental" that underlies legal advice and opinions).

5 See, e.g., K.K. DuVivier, E-Filing: Entering the Electronic Age-Part I, 32 Colo. LAW. 69, 69 (2003) (noting the trend in moving from paper to electronic communication); Robert M. Bastress \& Joseph D. Harbaugh, Taking the Lawyer's Craft into Virtual Space: Computer Mediated Interviewing, Counseling, and Negotiating, 10 CLINICAL L. REV. 115, 117 (2003) (noting that "communication[] in the computer age . . . affects lawyering").

6 See, e.g., Lisa G. Lerman, Lying to Clients, 138 U. PA. L. REV. 659, 708 (1990) (documenting lawyer interviewee who reported on one client who knew that lawyers "run the meter" and thus told his lawyers, "I don't want a single memo written about this [matter]").

7 See Charles Calleros, Traditional Office Memoranda and E-Mail Memos, in Practice and in the First Semester, 21 Perspectives: Teaching Legal Res. \& Writing 105, 105-06 (2013) [hereinafter First Semester], available at http://info.legalsolutions.thomson reuters.com/pdf/perspec/2013-spring/2013-spring.pdf (noting the debate about on-screen reading of legal memos).

8 See Lerman, supra note 6, at 708 (documenting the perceived link between writing memos and needlessly billing clients).

9 See Kristen Robbins-Tiscione, Ding Dong! The Memo is Dead. Which Old Memo? The Traditional Memo, SECOND DRAFT (Legal Writing Instit., Macon, Ga.), Spring 2011, at 6 [hereinafter The Memo is Dead] (quoting survey participant who said "[m]ost of my legal research is communicated by e-mail. It is relatively rare to be asked for a formal memo. Basically, the partners want new information, not redundancies in a specific format").

$10 \mathrm{Id}$. at 7 (noting that legal writing professors should "familiarize [students] with informal memoranda and e-mail [memoranda]"). See also Kristen K. Tiscione, The Rhetoric of E-mail in Law Practice, 92 OR. L. REV. 525 (2013) [hereinafter Rhetoric of Email] (discussing, in response to this article, her view on how e-mail memoranda are different from traditional memos).

11 See TOM Mighell, IPAD IN ONE Hour FOR LAWYers 46 (2011) (noting that the $\mathrm{iPad}$ is "extraordinarily well-suited for reading" and offering tips for viewing documents in a variety of formats). See also Dennis Kennedy, A Legal iPad, 96 A.B.A. J. 35, 35 (2010) ("[W]e are moving to an era of computing where we have more choices and are more likely to pick devices to fit our [reading] needs."); Ellie Margolis, Incorporating 
off the memo altogether or let it die what seems an inevitable death. ${ }^{12}$ As Kristen Tiscione has surmised from a recent survey of lawyers, "the traditional legal memorandum is all but dead in law practice."13

This tension over the legal memo's value and its need to change in light of new technology and lawyer expectations points to classic controversies about competent lawyering, effective communication of legal analysis, the types of legal writing that provide value to clients, whether lawyers "make" or "find" the law in the process of writing, and whether technology - the manner ${ }^{14}$ in which memos are produced and received - matters to reading and writing the law.

Writing legal memoranda is central to the lawyering experience and relies on core lawyering competencies-researching and understanding the law, applying law to facts, and conveying that analysis in writing. ${ }^{15}$ That is, understanding how the law impacts a client's facts provides the foundation for the rest of the lawyer's activities. Unless lawyers fully understand the relationship between memo writing and competency, however, lawyers are destined to undervalue the legal memorandum as an essential lawyering tool.

Electronic Communication into the LRW Classroom, 19 PERSPECTIVES: TEACHING LEGAL RES. \& WRITING 121, 121 (2011) (noting that lawyers are "reading . . . on a computer screen, BlackBerry, Droid, or iPhone"); The Memo is Dead, supra note 9, at 6 (noting the desire for more efficiency in practice).

12 See The Memo is Dead, supra note 9, at 6 (observing that lawyers in a survey "suggested that the traditional memorandum be deemphasized or even eliminated to include the forms students are more likely to use such as informal or short form memoranda and e-mail"); Kristen Konrad Robbins-Tiscione, From Snail Mail to Email: The Traditional Legal Memorandum in the Twenty-First Century, 58 J. LEGAL EdUC. 32, 32 (2008) [hereinafter Snail Mail], available at http://scholarship.law.georgetown.edu /facpub/798/ (noting survey results suggest "that the traditional legal memorandum is all but dead in law practice"); Margolis, supra note 11, at 121 (citing Tiscione for the assertion that "[t]he formal memo is on the decline").

13 See Snail Mail, supra note 12, at 32.

14 The notion that the manner in which writing is produced is a "technology" is not new. In fact, Walter Ong notes that "writing [itself] is a technology, calling for the use of tools and other equipment, styli, or brushes or pens, carefully prepared surfaces such as paper, animal skins, strips of wood, as well as inks or paints, and much more." Walter J. Ong, Writing is a Technology that Restructures Thought, in LITERACY: A CRITICAL SOURCEBOOK 22 (Ellen Cushman et al. eds., 2001).

15 See, e.g., Roy StUCKey eT AL., Best Practices For Legal EduCATION: A Vision AND A ROAD MAP (2007). Chapter two discusses various articulations of lawyering competencies, many of which include references to analysis, reasoning, communication, and research. In that chapter, the authors cite a study in which at least ninety percent of lawyers found "legal analysis and reasoning," "written communication," and "legal research" as "essential" or "very important" to law firm associates' success. Id. at 78. In addition, the authors discuss ABA Accreditation Standards that place emphasis on instruction in analysis, reasoning, research, and writing. Id. at 44 . 
Scholarship about reading and writing legal documents tends to focus on persuasive writing, perhaps because persuasive writing is more publicly observable in the form of briefs and motions. ${ }^{16}$ Little has been done, however, to interrogate the rhetorical, theoretical, and practical functions of the objective memo. And, the current literature on the subject shows that the intersection between legal writing, legal documents, and electronic composing and reading is only beginning to be understood. In fact, Ellie Margolis, in one of the few articles written about legal memos, notes that "[the] literature there is on the subject of electronic communication does not address [the] substantive component of how analysis [in a legal memo] conveyed via electronic device differs from traditional forms of legal writing." Accordingly, the goal of this Article is to explore the lawyer's common task of reading and writing legal memos in today's intensely technological world and assess the value of the objective legal memorandum for competent lawyering today. ${ }^{18}$

\footnotetext{
16 The few articles on objective memoranda, in addition to Tiscione's and Margolis's recent work, have been primarily instructional rather than interrogative. See, e.g., Bryan A. Garner, Sense and Sensibility: A Primer on Preparing Research Memos, 38 StUdent LAW. 12 (2010); John C. Kleefeld, Write Me A Memo, CAN. Legal EduC. ANN. ReV. 217 (2010); Terry Jean Seligmann, Why Is a Legal Memorandum Like an Onion? - A Student's Guide to Reviewing and Editing, 56 MERCER L. REV. 729 (2004). There are, of course, numerous legal writing texts that provide instruction on the objective memo. See, e.g., Charles R. Calleros, Legal Method and Writing (6th ed. 2011); Christine COUGHLin ET AL., A LAWYER Writes: A PRACTICAL GUide to LEgal ANALYSiS (2008); LAUREL CuRrie OATS \& ANNE ENQuist, THE LEgal Writing haNdBoOK: ANALYSIS, RESEARCH AND WRITING (5th ed. 2010). On the other hand, there are numerous articles interrogating persuasion from philosophical and empirical perspectives. See, e.g., Linda L. Berger, The Lady, or the Tiger? A Field Guide to Metaphor and Narrative, 50 WASHBURN L.J. 275 (2011); Judith D. Fischer, Got Issues? An Empirical Study about Framing Them, 6 J. ASs'N LEGAL WRITING DiRECTORS 1 (2009); Michael J. Higdon, Something Judicious This Way Comes . . The Use of Foreshadowing as a Persuasive Device in Judicial Narrative, 44 UNIV. RICH. L. REV. 1213 (2010); Lucille A. Jewel, The Bramble Bush of Forking Paths: Digital Narrative, Procedural Rhetoric, and the Law, 14 YAle J.L. \& TeCH. 66 (2011); Jennifer Sheppard, Once Upon A Time, Happily Ever After, and in a Galaxy Far, Far Away: Using Narrative to Fill the Cognitive Gap Left by Overreliance on Pure Logic in Appellate Briefs and Motion Memoranda, 46 WiLlamette L. ReV. 255 (2009); Kathryn M. Stanchi, The Power of Priming in Legal Advocacy: Using the Science of First Impressions to Persuade the Reader, 89 OR. L. REV. 305 (2010); Kathryn M. Stanchi, Playing With Fire: The Science of Confronting Adverse Material in Legal Advocacy, 60 RUTGERS L. REV. 381 (2008).

17 Margolis, supra note 11, at 125.

18 As a scholar, I take seriously the call for academics and lawyers to "make lawyering a subject of inquiry." GARY Bellow \& BeA MOUlton, THe LAWYERING Process: MATERIALS FOR CLINICAL INSTRUCTION IN ADVOCACY xix (1978).
} 
This Article resurrects the "dead" memo; it takes up the question of the present value of the objective legal memo and explores its history, examining a memo's function and how that function relates to lawyer competence. It examines how the legal memo intersects with reading "on the screen" and offers a philosophical and practical approach that does not bury the legal memo. Instead, the Article joins legal reasoning, legal ethics, rhetorical theory, cognitive science, and reading studies to resurrect the legal memorandum as a critical document of legal practice. This Article rejects the idea that there are foundational differences between formal and informal legal memoranda, that the traditional legal memo is (or should be) "dead," and that emerging technology requires a substantial revision of how legal memoranda are written. ${ }^{19}$ Instead, this Article asserts that new media should not (re)define the classic message of the legal memo simply because the lawyer's computing work-style might lend itself to the expediencies of browsing, skimming, and surfing. Rather, the persistent complexities of law and the ubiquity of written communication as the means for conveying legal analysis demand fundamental and thorough legal communication practices to help ensure that lawyers are giving competent legal advice in any medium.

Critical thinking and careful reasoning are still at the core of a lawyer's intellectual duties, and exploring legal analysis in writing is an essential component of meeting that duty. Writing and reading in a computer-mediated milieu requires understanding that producing and reading texts are sense-making, judgment-making, decision-making activities taking place within multiple contexts. $^{20}$ A full understanding of the memo's role requires considering the "complex interrelation of literacy, technology, thought, and society.,"21

Marshal McLuhan famously said that "the medium is the message," meaning that the communication technology shapes and transforms the nature of human interaction. ${ }^{22}$ In many ways, this Article is about the intersection of the medium and the message in reading and writing objective legal memoranda. Accordingly, this

\footnotetext{
19 See also First Semester, supra note 7 (describing recent debates about the usefulness and nature of the legal memo).

20 Thinking of the objective legal memo this way means thinking about the memo as the product of a rhetorical act in response to a rhetorical situation. See Lloyd F. Bitzer, The Rhetorical Situation, 1 PHIL. \& RHETORIC 1 (1968) (discussing the rhetorical situation).

21 Ong, supra note 14, at 5.

22 Marshall Mcluhan, Understanding Media: The Extensions of MAN, at vi (1964).
} 
Article does two things. First, it attempts to rethink the message of the legal memo - to envision the memorandum as an essential rhetorical act of legal writing, reading, creating, critiquing, and analyzing, rather than as an unnecessary, redundant, or a frivolous act of legal documentation or regurgitation. Second, it attempts to rethink the effect of the medium on the message - to look at the challenges facing the legal memorandum from the increase in lawyers reading and writing on the screen.

This Article first reviews the rhetorical situation for memo writing and how the perception of reading and writing memos has changed as a result of emerging on-screen reading technology, including mobile technology. Then, it outlines the current debate surrounding objective legal memos, arguably brought on by changes in legal technology and the legal marketplace. The Article then addresses these arguments by discussing the importance of writing and structure to legal advice giving. It argues that "on-screen" reading does not create a new legal memo category and asserts that attempts to carve out "substantive email" memos and "informal" memos as separate types of documents are misguided. Finally, it demonstrates that all memos are essentially of the same category by reviewing the kinds of text structures that are important to legal memo writing, whether read "on-screen" or off. The Article concludes by rejecting the critiques of the "traditional" objective legal memo and describes an approach to objective memo writing that can meet audience needs well into the future. ${ }^{23}$

\section{I}

THE RHETORICAL SITUATION FOR THE LEGAL MEMORANDUM

To understand the function of a legal memo, it is critical to understand the rhetorical situation in which the memo is written. Three parts comprise the rhetorical situation:

- "An imperfection marked by urgency" that rhetoric can productively address;

- An audience capable of being influenced by rhetoric; and

23 Professor Tiscione has crafted a thoughtful response to my claim that e-mail is not a new legal writing category in her accompanying article. See Rhetoric of E-mail, supra note 10. I acknowledge and appreciate her friendship as well as her willingness to publicly debate these issues that will impact legal writing in the foreseeable future. I hope that these articles, considered together, will engender spirited debate amongst readers. 
- Situational constraints that include "persons, events, objects, and relations [that] have the power to constrain decision and action." 24

The rhetorical situation for reading and writing legal memos in today's legal culture involves primarily three components - the need for competent advice giving, the advent of computing and mobile technology, and the demand for greater efficiencies in lawyering. The confluence of these situational characteristics has given rise to concerns about the usefulness of the "traditional" objective memorandum, which are described in Part II.D. But before turning to these concerns, the situational characteristics are discussed below.

\section{A. Handling the "Imperfection": Lawyers (Still) Have a Duty to Give Competent Advice}

Typically, the urgency that lawyers address with a legal memorandum is the need for one lawyer to communicate the law to another and, often, to advise the other about the law's application to a specific set of client facts. The rest of lawyers' practice-giving advice, making arguments in trial, negotiating contracts, or mediating claims, for example - is based upon this carefully considered analysis of how the law governs the client's facts. Without this foundation, a lawyer's work may prove incompetent.

Notably, the very first rule of the Model Rules of Professional Conduct requires that lawyers act with competence. ${ }^{25}$ This requirement is grounded substantially in the lawyer's duty to understand the law and to assess client facts. The Model Rules state that the most fundamental lawyering skill is "determining what kind of legal problems a situation may involve," and "analy[zing] the factual and legal elements of the problem." ${ }^{, 26}$ Adequate preparation is

${ }^{24}$ Bitzer, supra note 20 , at 8 . Rhetorical theory, from which the idea of the rhetorical situation is drawn, is essential to examining objective memorandum writing because "[r]hetorical theory takes as its object the text." Jeff Todd, The Rhetoric of Recognition, 45 MCGEORGE L. REV. (forthcoming 2013). "Rhetoric posits that meaning and power reside in the textual relationship"; accordingly, a careful examination of a text's rhetorical character can illuminate how a memo's author, audience, text, and context relate to one another. See Jeff Todd, A Rhetoric of Warning Defects, 54 S. TEX. L. REV. (forthcoming 2013).

25 MOdel Rules OF Prof'L CONDUCT R. 1.1 (2013).

26 Id. at cmts. 1 \& 5. The McCrate Report from 1992 also identified problem solving, legal analysis and reasoning, and factual investigation all as fundamental lawyering skills. See ABA SECTION OF LEGAL EDUC. \& AdMisSiONS tO THE BAR, REPORT OF THE TASK FORCE ON LAW SCHOOLS AND THE PROFESSION: NARROWING THE GAP 136 (1992). 
also essential, according to the Rules. ${ }^{27}$ Competence demands that lawyers have the "knowledge" as well as the "preparation" necessary for giving the advice. ${ }^{28}$ Key to this preparation is "analysis of precedent" and the "evaluation of evidence" 29 - two analytical and rhetorical actions that take place while constructing a legal memorandum.

The objective memorandum arguably is a core component of competency, particularly as it pertains to advice giving during representation. ${ }^{30}$ Legal memoranda allow lawyers to reason through the law and facts, to construct and create arguments and advice, and to document or convey that analysis from one lawyer to another. For example, the New York Times recently reported that lawyers in the Obama administration wrote a fifty-page internal memorandum analyzing, and ultimately supporting, the administration's decision to kill an American citizen hiding in Yemen. ${ }^{31}$ The New York Times reported that the memo gave "a glimpse into the legal debate" that involved "months of extensive interagency deliberations." ${ }^{32}$ Using the terms that describe the rhetorical situation, this memo, and the thousands of others that support legal decision making, is a response to legal "imperfections" and the need to respond to them with sound advice and action.

\section{B. Reading and Writing: Electronic Technology Impacts the Situation}

A lawyer's ability to construct and convey competent legal advice-a quintessentially traditional lawyering task-is today immersed in a culture of rapidly advancing communication and composition technology. In other words, lawyers are reading and writing in ways not contemplated twenty, even ten, years ago and in ways that are unique to their own practices and preferences. "With

\footnotetext{
27 Model Rules of Prof'L CONDUCT R. 1.1 cmt. 5 (2013).

$28 I d$. at $\mathrm{cmt} .1$.

29 Id. at cmt. 2.

30 Restatement (ThiRd) OF THE LAw Governing Lawyers § 46, cmt. d (2000) (specifically mentioning "legal memoranda" in the types of documents that relate to the representation).

31 Charlie Savage, Secret U.S. Memo Made Legal Case to Kill a Citizen, N.Y. TIMES, Oct. 8, 2011, at A1, http://www.nytimes.com/2011/10/09/world/middleeast/secret-us -memo-made-legal-case-to-kill-a-citizen.html?pagewanted=all.

$32 I d$.

33 Kennedy, supra note 11, at 35 ("[W]e are moving to an era of computing where we have more choices and are more likely to pick devices that best fit our needs.").
} 
today's communication [processes] converting from paper to electronic format, [lawyers live] in an age of transformation. . . . This shift will metamorphose the way lawyers and judges read-and write-legal documents." 34

The advent of computers, and most recently, mobile technology, has altered the way lawyers communicate. ${ }^{35}$ These changes act as a constraint on the way lawyers respond to and communicate about the legal situations confronting them. Experts in digital technology for law practice are writing about new legal reading technologies. Experts agree that "e-readers are the next great tool of the industry," and that the iPad may become the new legal pad. ${ }^{36}$ Audiences of legal documents want to be able to read those documents on iPads, iPhones, Blackberries, Android tablets, and computer screens. ${ }^{37}$ Moreover, they want this electronic information to be both portable and easily accessible. ${ }^{38}$ With respect to the iPad in particular, experts suggest that it is a useful tool when it comes to reading legal documents, ${ }^{39}$ and reading on the iPad, for example, is easy, and more apps are developing that allow lawyers to view various PDFs and text files. Lawyers report that the iPad allows them to "flip through the pages and everything is there." ${ }^{40}$ In a book for lawyers on how to learn to use an iPad in one hour-the author notes the "ease of reading on the iPad" and offers tips for viewing various documents in a variety of formats. ${ }^{41}$ Even United States Supreme Court Justices Elena Kagan and Antonin Scalia read briefs on new media technology, Kindle and iPad, respectively. In a recent interview,

\footnotetext{
34 DuVivier, supra note 5, at 69.

35 Bastress \& Harbaugh, supra note 5, at 117 ("[T]ransformation of [legal] communications in the computer age ... affects lawyering since so much of what lawyers do involves the art and science of communicating.").

36 Kennedy, supra note 11, at 35.

37 See, e.g., Sylvia Hsieh, Lawyers Audition the iPad in and out of Court, LAW. U.S.A., Apr. 30, 2010, at 1 (noting that " $[1]$ awyers are ... using [the iPad] in their daily commutes to read e-books, conduct legal research and review documents").

38 See, e.g., Travis Andrews, Technology has Revolutionized the Law, but Apps Marketed to Lawyers Mostly Ignored, S.C. LAW. WKLY., June 17, 2011, at 1 (noting that lack of wi-fi is a "big[] inconvenience[]" for lawyers who want to "connect to [] documents from anywhere").

${ }^{39} \mathrm{Id}$. Other sources have suggested that the primary purpose of the iPad is as a content reader. See, e.g., Hsieh, supra note 37.

$40 \mathrm{Id}$. at 2.

41 Correy Stephenson, Lawyers Can Learn to Use the iPad in One Hour, LAW. U.S.A., May 31, 2011, at 6 (citing TOM Mighell, IPAD IN ONE HOUR FOR LAWYERS (2011)).
} 
Justice Kagan noted that "if a Kindle or an iPad can make [reading documents] easier, that's terrific." 42

With respect to writing with mobile technology, lawyers want to be able to do up-to-the-minute research and have access to word processing on everything from their smart phone to their computer. ${ }^{43}$ Westlaw, for example, has a mobile application, and the word processing capabilities on mobile technology continues to improve. ${ }^{44}$

\section{It's Tough Being a Lawyer}

After the financial downturn, many would argue, the constraints of practice placed upon lawyers are greater than ever. ${ }^{45}$ Today's clients demand legal services for less money. ${ }^{46}$ Lawyers are expected to bill more than ever, to learn with less mentoring, and to produce documents more quickly. ${ }^{47}$ Components of the lawyer's work have been criticized as unnecessary, redundant, and ripe for commodification. ${ }^{48}$

42 Interview with Elena Kagan, Supreme Court Justice of the United States Supreme Court, C-SPAN (Dec. 10, 2010), available at $\mathrm{http}: / / \mathrm{www} . y o u t u b e . c o m / w a t c h ? \mathrm{v}=1 \mathrm{~J} 7 \mathrm{xlku}$ Tvvo.

43 Andrews, supra note 38, at 2 (quoting lawyer who stated that "I'll generate four- or five-page memos off my Blackberry").

44 See GET THE iPad APP, WESTLAWNEXT, http://info.legalsolutions.thomsonreuters .com/westlawnext/mobile-ipad/ipad-app/default.aspx (last visited Nov. 18, 2013); Apple, Pages, http://www.apple.com/apps/iwork/pages (last visited Dec. 12, 2013); see also Jeff Richardson \& Jeff Taylor, Mobile Apps For Lawyers: 11 Must-Have Apps for Lawyers, A.B.A. J.COM, http://www.abajournal.com/gallery/mobilelawyerapps (last visited Oct. 24, 2013) (including e-document readers and research apps in their list of "must haves").

45 Mark Koba, Courtroom Drama: Too Many Lawyers, Too Few Jobs, CNBC (Mar. 21, 2013, 12:01 PM), http://www.cnbc.com/id/100569350 (noting that "[b]ecause of the recession of 2007-2009 and a still-struggling economy, the legal profession is under severe stress").

46 See Debra Cassens Weiss, Finicky In-House Counsel Refuse to Pay Law Firms for 'Legal Miscellany', A.B.A. J.: LAw NEws Now (Oct. 22, 2012, 7:20 AM), http://www.aba journal.com/news/article/finicky_in-house_counsel_refuse_to_pay_law_firms_for_legal _miscellany/ (noting how in-house counsel scrutinize bills more closely).

47 See Michael Duncan, Bridging the "Mentoring Gap," THE BENCHER, Jan.-Feb. 2011, at 1, 1 (noting a decline in the mentoring of young lawyers); Debra Cassens Weiss, 'Better-Faster-Cheaper' Work Model for Lawyers Has Led to Burnout, NY Bar Report Says, A.B.A. J.: LAW NEwS Now (Feb. 4, 2011, 9:02 AM), http://www.abajournal .com/news/article/better-faster-cheaper_work_model_for_lawyers_has_led_to_burnout ny_bar_repo/.

48 See Richard Susskind, THE END OF LAWYERS? RETHINKING THE NATURE OF LEGAL SERVICES 1-2, 13 (Oxford 2008) (stating that "many aspects . . of the way we practise law . . . can and should be enhanced or even replaced by computer technology"; noting that "[c]ommoditatization and IT will shape and characterize twenty-first century 
In this environment, the pressure is on lawyers to be ethical and competent with less time and money to spend. Without a better understanding of the way the objective legal memo helps a lawyer meet the duty of competency, it may be easy, within the constraints of this high pressured environment, to reject objective memo writing altogether.

\section{D. "Substantive" E-mail and the Death of the Traditional Memo}

As "nontraditional," electronic modes of writing and reading grow, and the preferences of lawyers (and clients) in today's legal market change, the usefulness of the traditional legal memo has come under attack. Certainly, there is fluidity in the term "traditional legal memo," and different writers have used the term in different ways. For the purposes of this Article, however, "traditional" means a memo that is based upon the "classic" or "comprehensive" structure ${ }^{49}$ and contains most or all of the following parts: question presented, brief answer, statement of facts, discussion, and conclusion.

Critiques of the traditional legal memorandum that suggest it is an outdated or inefficient way for conveying legal analysis point to technological advancements, efficiencies, and client demands as the death knell for the traditional memo. ${ }^{50}$ For example, the move toward a technological medium has resulted in some scholars' calls for a move away from the traditional memo to the "informal memo" or "substantive e-mail" memo as a new way of structuring thought, communicating the results of research, and laying the foundation for legal advice. ${ }^{51}$

Two articles in particular reflect the circulating critiques of the legal memo. First, in 2006, Kristen Tiscione surveyed Georgetown graduates regarding the value of legal memorandum in legal practice. ${ }^{52}$ Tiscione found that seventy-five percent of respondents

legal service"; and explaining that "the market is increasingly unlikely to tolerate expensive lawyers for tasks . . . that can equally or be better discharged by less expert people, supported by sophisticated systems and processes").

49 This structure was discussed as early as the 1940s and 50s in bar magazine articles; they arguably represent the birth of the traditional interoffice legal memorandum. See infra Part II.A.4.

50 See Snail Mail, supra note 12, at 36, 42 (describing her survey participants' reasoning for seeing the traditional memo as less useful in today's practice setting and the connection to the usefulness to the e-mail format).

51 Id. at $48-49$.

52 Id. at 32 . 
said they wrote no more than three legal memoranda a year. ${ }^{53}$ Instead, respondents said they were more inclined to write "substantive" emails, defined "as a message containing substantive information and not serving simply to forward an attachment," 54 and "informal memos," defined as "a statement of the legal issue and the attorney's conclusion or advice, followed by supporting analysis." found that survey participants said that legal memoranda, in the traditional sense, were discouraged by clients because they were costly, not useful, or not an efficient use of time; participants also expressed that the underlying document (that presumably would result from the research in the memo) was easier to draft than the memo itself. $^{56}$ She further found that "attorneys are using e-mail to practice law in new ways that reflect their clients' growing demands for quick response time and simple, straightforward advice." 57 Ultimately, Tiscione argues that substantive e-mail and informal memos should be favored over a traditional memo, because their elements are "organic" whereas the elements of the traditional memo are "static.,"58 And, she concludes that traditional memoranda are a "dying breed" and will be replaced by informal memoranda and substantive email. ${ }^{59}$

In addition to cost and efficiency, which seemed to drive the preferences of those lawyers surveyed in Tiscione's study, Ellie Margolis has identified reading on the screen as another possible reason to trade the traditional memo for the e-mail memo. ${ }^{60}$ In her

53 Id. In her article, Tiscione asks respondents about memoranda addressed to clients. Id. This article, however, focuses on memoranda addressed to other lawyers. Accordingly, Tiscione's findings only have partial application to this article, which focuses on the use of the memorandum as lawyer-to-lawyer communication. See also LINDA H. EDWARDS, LEGAL WRITING AND ANALYSIS 131 (3d ed. 2011) ("An office memo is an internal working document of a law firm or other office. It is not designed for outside readers (...").

54 Snail Mail, supra note 12, at 42.

55 Id. at 33.

56 Id. at 36. See also Posting of Lisa Healy, to LRWPROF-L@LISTSERV.IUPUI.EDU (Mar. 1, 2011) (on file with author) (noting that at the New England LRW consortium, practitioners reported "shorter analysis via e-mail is more common"); but see First Semester, supra note 7, at 106 (noting that "traditional office memoranda remain valuable vehicles for conveying research and analysis in major cases, when the issues are complex and the stakes justify the cost").

57 Snail Mail, supra note 12, at 34.

58 Id. at 33.

59 See id. at 49.

60 Margolis, supra note 11, at 121. 
article that focuses on teaching e-mail communication, Margolis assesses "the needs of the reader" in the context of electronic communication. ${ }^{61}$ These needs include "the need for a clear, up-front answer and succinct analysis as well as the importance of organization, bearing in mind that the message may be viewed on a variety of different electronic devices." ${ }^{2}$ Accordingly, Margolis concludes that

[e]-communication call[s] for a different kind of writing than is traditionally covered in a legal research and writing course. It [isn't] just a brief answer plunked into an e-mail. It [is] longer, and organized differently than a brief answer would be, yet [is] still a concise summary of the analysis of the client's problem. ${ }^{63}$

Recently, legal writing textbook authors have begun incorporating into their textbooks the new memo category description, the "e-mail memo,"64 a term which can refer to either the delivery method or memo content or both. The textbooks, however, are inconsistent on when an electronically-delivered memorandum (whether in the body of the e-mail or as an attachment) should be used by a legal writer,

\footnotetext{
61 Id. at 123 .

$62 \mathrm{Id}$.
}

${ }^{63} \mathrm{Id}$. at 124. Margolis was assessing e-mail memos in the context of the legal writing classroom. She had directed students to provide in the e-mail, a "summary of their analysis." Id. In evaluating student performance, Margolis noted that "[e]ven students who were weaker analytically, or who had difficulty with writing clear, direct prose, did a very good job summarizing their analyses clearly in the electronic context." Id. She further noted that students liked the lack of form. Id. As will be discussed further, this is exactly the concern the author has with the move toward identifying a new genre of the "e-mail memo" in the context of teaching legal writing; there is a tendency for the e-mail or informal memo to be interpreted as a "summary" and thus, may encourage the glossing over of essential analysis, particularly by novice legal writers. While this gloss might be appropriate in some contexts of lawyer-to-client communication where depth of analysis is not needed for the client to understand and implement advice, summarizing is not appropriate for lawyer-to-lawyer communication in a legal memorandum where the summary eliminates critical detail. Furthermore, a more structured form of the legal analysis can drive careful analysis; having a "lack of form" may discourage this rigor. See infra Part II.A.5. In other words, in this author's opinion, students new to legal writing would find drafting an e-mail "summary" memo easier because it requires less rigorous thinking and writing, even though it might make for easier (and perhaps less informative) reading. Thus, even though this author agrees that effective summarizing is an important skill legal writers should have, legal writers must understand that summarizing is not equivalent to the analysis that is needed for a carefully written legal memorandum.

64 See, e.g., Richard K. NEUMANN \& SHEILA SimON, LEGAL Writing 194-95 (2011) (using the term "email memos" and noting that since they have "developed very recently ... . there's no consensus on their format"). See CALLEROS, supra note 16, at 206 (identifying the "streamlined email memo"); COUGHLIN ET AL., supra note 16 (distinguishing between an "office memorandum" and an e-mail). 
and the books offer a wide range of advice. Some textbooks draw little attention to the different delivery modes for legal memoranda noting that "[v]ariations in format are much less important than the accuracy and thoroughness of the analysis." ${ }^{65}$ Other textbooks, however, even when they agree that the content of the memo is more important than the transmission mode, ${ }^{66}$ offer a range of sometimes conflicting advice about when e-mail memoranda should be used, stating they should be used:

- When the legal analysis will not fill more than one computer screen; ${ }^{67}$

- When the e-mail will be no longer than a page and contains little more than what would be included in a conclusion or brief answer of a "full-scale memo"; 68

- To convey a shorter analysis; ${ }^{69}$

- To "streamline" an analysis so that an assigning attorney can gain access to the text through any hand-held device; ${ }^{70}$

- When a supervisor needs an "analysis faster and more concisely than an office memo could provide", ${ }^{71}$

- When a supervisor needs to be able to "read and understand it within moments of opening it"; ${ }^{72}$ but

- Not when the memo is of the type to have been traditionally in hard copy. ${ }^{73}$

The lack of consistency in terminology, definition, and approach to contemporary legal memo writing in an electronic setting suggests confusion and controversy about whether the purpose of the legal analysis contained in an objective memo is different where busy readers are using computer screens and mobile technology to read memos. In fact, at least one textbook says e-mail memos are meant to

\footnotetext{
65 EDWARDS, supra note 53, at 131.

66 See COUGHLIN ET AL., supra note 16, at 10 (any memo must "convince another attorney that your analysis is sound").

67 Id. at 4.

68 NANCy L. Shultz \& Louis J. Sirico, JR., Legal Writing AND Other LAWYERING SKILLS 210 (5th ed. 2010).

69 CALlEROS, supra note 16, at 206.

70 COUGHLIN ET AL., supra note 16, at 4.

71 NeUmANN \& SimON, supra note 64, at 193.

$72 \mathrm{Id}$.

73 SHULTZ \& SIRICO, supra note 68, at 210 ("An e-mail is not a venue for a complete memo of the sort that you might compose in hard copy.”).
} 
be different. ${ }^{74}$ They are "briefer documents that can be read and digested in a short time," and convey the equivalent of the brief answer or conclusion in a traditional memo. ${ }^{75}$

This Article asserts that e-mail memos are not different such that they are a new category of memoranda that has taken, or should take, the place of traditional memoranda. Rather, this Article asserts that email memoranda are well within the flexible boundaries of the "traditional" category. Further, this Article demonstrates why the traditional objective memorandum, if lawyers care about competent advice giving, should be alive and well in an on-screen reading and writing culture. ${ }^{76}$

\section{II}

\section{EVERYTHING OLd IS NEW AgAIN: THE DANGERS OF KILLING OFF THE TRADITIONAL MEMO}

The idea that the "traditional" memorandum is out-of-date as a means of lawyer-to-lawyer communication in an electronic world is deceptively appealing. Lawyers want information faster, easier, and more cost-effectively. Lawyers read on the screen, and that screen is getting smaller and smaller. Sometimes the traditional legal memorandum seems redundant and is often perceived by clients to be a worthless fee-generator. Yes, taking these statements at face value makes it easier to believe that traditional objective legal memoranda have passed their prime, except perhaps in rare cases where complexity demands a print document. ${ }^{77}$

However, this view overlooks three important arguments in favor of a renewed commitment to the traditional legal memorandum. This Part sets out those arguments in some depth but starts by outlining them below.

Just because lawyers might want "shorter" memos, on-screen or otherwise, this does not mean that shorter memos are suitable for either legal readers or legal writers.

\footnotetext{
${ }^{74} I d$.

$75 \mathrm{Id}$.

76 It is important to note that none of the textbook authors cited in this article have advocated for abandoning the office memorandum in the traditional form as a teaching tool or as a viable document for practice.

77 SHULTZ \& SIRICO, supra note 68, at 210 ("If your supervisor wants a full-scale memo, you should produce a hard copy or place it in an attachment [to the e-mail] that he or she can download and print.").
} 
Some suggest that new communication media requires that objective legal memos must be written to meet the demands for "easier" and "quicker" reading. ${ }^{78}$ This arguably means writing differently when the memo will be transmitted by e-mail or read on a screen. This point, however, overlooks how writing the "traditional" legal memo is essential to the advice-giving process. Because legal memo writing is an intersubjective, deliberative, and rhetorical act that leads to advice giving, writing the legal memo can play an important role in ensuring that lawyers have met their duty to give competent advice. That is, because legal advice giving is impacted by the dangers associated with intuitive decision-making processes, implicit biases, and logical fallacies, memo writing provides a structure that can force improved deliberative decision making. By engaging in the summarizing, short-form writing that lawyers (or their clients) apparently want in reading e-mail or informal memos, writers run the risk of giving readers what they should not want-poorly thought-through legal analysis. In other words, a memo, whether electronic, formal, informal, or streamlined, should use the number of words and paragraphs necessary to convey a solid, well-thought-out legal analysis.

"On-screen" is not a new legal writing category for objective memos.

Another argument in favor of moving away from the "traditional" objective memorandum toward an "informal" memo or "substantive e-mail" is that reading legal memoranda on a screen is (and, perhaps, should be) fundamentally different than reading that analysis on paper. Thus, the argument goes, an "informal" memo or "substantive" e-mail structure should replace a traditional memo structure because technology requires it. That is, legal readers read legal memoranda differently on the screen and therefore should get a different kind of legal memorandum as a result.

Because flexibility has always been a feature of the traditional memorandum, however, the notion that a different category of legal memo has emerged is incorrect. Instead, e-mail or on-screen memoranda should be appropriately comprehensive for their topics and as formal as necessary to include sufficient information for the reader to understand the reasoning and analysis and implement the

78 CALLEROS, supra note 16, at 207 (noting reader's need for easy access); NEUMANN \& SIMON, supra note 64, at 193 (noting a supervisor's need for faster and more concise analysis in e-mail). 
advice. By starting with the traditional structure and then exploring its flexible application to different kinds of legal issues, the legal writer is more likely to write a competent memo, and the legal reader is more likely to comprehend the information it conveys.

Traditional organizational strategies are more important than ever.

Finally, the critique of the traditional memo suggests that electronic technology somehow spawns a heretofore unencountered legal reader who requires a writer to implement fundamentally new strategies for conveying information. In the context of writing legal memoranda, this argument misses two points. First, while readers are impatient, impatient legal readers are nothing new. Second, and more importantly, although research shows that readers may somewhat differently read and comprehend on-screen texts, nothing suggests that the basic tenets for structuring comprehensible documents have changed simply because readers will read those documents on the screen. Therefore, the legal memorandum needs to use the "formal" text structures that have always facilitated reader navigation, critical reading, and comprehension. In fact, the classic organizational structures that have been available to legal writers for decades are even more powerful when used to draft documents for electronic media. If anything, contemporary media demands a return to classic techniques to improve reader speed, comprehension, and satisfaction.

\section{A. "Shorter" and "Easier" Is Not Necessarily Better: Competent, Deliberative Decision Making Through Writing}

A legal memo, whether transmitted by paper, e-mail, or otherwise, does more than simply convey law and analysis that existed prior to the act of writing. Rather, a memo is a present process by which law and fact come into being through the deliberative and interpretive acts of the writer. ${ }^{79}$ As a rhetorical process constitutive of the law and analysis it conveys, ${ }^{80}$ a memo's objective analysis is paradoxically the

\footnotetext{
79 James Boyd White, Imagining the Law, in THE RHETORIC OF LAW 29, 35, 41 (Austin Sarat \& Thomas R. Kearns eds., 1996) [hereinafter Imagining the Law] ("The lawyer's task is not just to apply rules in a mechanical way, then, but to learn how to think and argue about their meaning .... The person doing a good job of drafting ... engages in an activity of the dramatic imagination ....").

80 James Boyd White, Law as Rhetoric, Rhetoric as Law: The Arts of Cultural and Communal Life, 52 U. CHI. L. REV. 684, 684 (1985) [hereinafter Law as Rhetoric].
} 
product of intersubjectivity, which is the act of meaning-making that occurs between writer, reader, text, and context. ${ }^{81}$

Not only is memo writing the product of intersubjectivity, it is also a core component of the advice-giving function and lawyer competence. As both a creative and ethical task, ${ }^{82}$ memo writing is fraught with the dangers associated with bias and intuitive decision making. ${ }^{83}$ Yet, the deliberation that can occur through writing acts as a check on cognitive bias and fallacies of reasoning. It provides a space where legal writers can be skeptics of their own thinking and doubt their own conclusions in an effort to shore up the accuracy and precision of their analyses. Accordingly, simply because readers might want "simple" or "summary" answers to a legal question in a document that will be read on a screen does not mean that writers should be any less rigorous in the process of constructing memoranda. Although " $[\mathrm{t}]$ he myth persists that technology eases thought, [it] in fact . . . requires even more creative thinking." ${ }^{\circ 4}$ This section describes how and why the need for creative, deliberative memo writing is important to both the writer and the reader.

\section{Lawyers and the Advice-Giving Function: The Duty to Doubt}

As a baseline ethical obligation, lawyers are expected to give competent advice, even if that advice is not well received. At minimum, competency requires that lawyers have the "knowledge" and "preparation reasonably necessary for the representation.,"85 Malpractice case law further establishes that competency requires lawyers to undertake reasonable research. ${ }^{86}$

\footnotetext{
${ }^{81} \mathrm{Id}$. (discussing the ways in which a rhetorical view of reading and writing the law join reader, writer, and context).

82 Law as Rhetoric, supra note 80, at 690 ("Every time one speaks as a lawyer, one establishes for the moment a character - an ethical identity ....”).

83 See infra Part II.A.3.

${ }^{84}$ Nelson P. Miller \& Derek J. Witte, Helping Law Firm Luddites Cross the Digital Divide-Arguments for Mastering Law Practice Technology, 12 SMU SCI. \& TECH. L. REV. 113, 120 (2009).

85 MOdel Rules OF PROF'L CONDUCT R. 1.1 (2013), available at http://www.american bar.org/content/dam/aba/administrative/professional_responsibility/mrpc_1_1.authcheck dam.pdf (noting, most states have adopted Rule 1.1 in the form drafted by the ABA).

86 See, e.g., Lopez v. Clifford Law Offices, P.C., 841 N.E.2d 465, 471 (Ill. App. Ct. 2005) (noting that it is negligence to misadvise a client based upon failure to look up a point of law that could be found by means of ordinary research steps).
} 
Malpractice case law has also described competency as the duty of lawyers to make reasoned informed judgments. ${ }^{87}$ Lawyers are expected to make an "intelligent evaluation of the case" 88 and to "examine the law and facts relevant to the representation." 89 This includes "analysis of precedent, the evaluation of evidence," "inquiry into and analysis of the factual and legal elements of the problem," and, perhaps most fundamentally, "determining what kind of legal problems a situation may involve." 90

In legal memoranda, lawyers are expected to give advice that reflects "independent professional judgment" "91 and that is "straightforward advice expressing the lawyer's honest assessment," even when the reader of the memo might disagree with the advice or the analysis in the memo is controversial or unfavorable. ${ }^{92}$ Advice giving also requires that lawyers address "unpleasant facts and alternatives that a client may be disinclined to confront." 93 This includes carefully "consider[ing] both sides of the legal and factual story they seek to advance." 94 Recognizing conflicts in law and facts are a signal that the "analytical process is strong and capable." 95

\footnotetext{
87 See, e.g., Biomet Inc. v. Finnegan Henderson LLP, 967 A.2d 662, 666 (D.C. 2009) (noting, in a judgmental immunity case, that lawyers are obligated to act "in good faith and upon an informed judgment after undertaking reasonable research of the relevant legal principals [sic] and facts of the given case"); Blanks v. Seyfarth Shaw LLP, 171 Cal. App. 4th 336, 344 (2009) (noting that lawyers' decisions "must be informed [and] based upon intelligent evaluation of a case"); Janik v. Rudy, 119 Cal. App. 4th 930, 937 (2004) (noting the same).

88 Blanks, 171 Cal. App. 4th at 344.

89 U.S. v. Russell, 221 F.3d 615, 620 (4th Cir. 2000).

90 Model Rules of Prof'L CONDUCt R. 1.1, cmt. 2, 5 (2013), available at http://www.americanbar.org/groups/professional_responsibility/publications/model_rules _of_professional_conduct/rule_1_1_competence/comment_on_rule_1_1.html.

91 Id. at R. 2.1.

92 Id. at $\mathrm{cmt} .1$.

$93 \mathrm{Id}$.

${ }^{94}$ Lisa T. McElroy \& Christine N. Coughlin, The Other Side of the Story: Using Graphic Organizers to Counter the Counter-Analysis Quandary, 39 U. BALT. L. REV. 227, 228 (2009) (citing Model Rule of Professional Conduct 3.3, which addresses candor to the tribunal). Interestingly, Arthur Miller complained about the idea that an argument has only "two sides," represented by the analysis and counter analysis. See Arthur Selwyn Miller, The Myth of Objectivity in Legal Research and Writing, 18 CATH. U. L. REV. 290, 291-92 (1968). He mused that "[t]he adversary system places a premium on partisan pursuit. [Lawyers] look upon these disputes as being essentially two-sided . . ., but the hard reality is that there may in fact be many facets." Id. Accordingly, "it may readily be seen that the adversary system tends to create simplistic 'solutions' to what really are immensely complex problems." Id. at 292.

95 McElroy \& Coughlin, supra note 94, at 232.
} 
At the core of competency and the advice-giving function is what this author calls the "duty to doubt." The duty to doubt requires that for a lawyer to be competent in advice giving, the lawyer must approach the task with an attitude of skepticism, curiosity, and challenge. ${ }^{96}$ The lawyer's motivation must be to treat the law and the facts as open but not boundless, subject to perspective, and made up of norms, principles, rules, and ideas that exist both inside and outside of official legal discourses. In other words, to fulfill her duty to doubt, a lawyer must understand that every time the law is written about and read, it is interpreted and transformed, and the lawyer doing the writing or reading plays a role in that interpretation and transformation. ${ }^{97}$ Ultimately, the duty to doubt enables lawyers to see the law and the facts of any given case as rhetorical, the product of motivated language in a situated context, where meaning is subject to shift, and where "doubt" opens the law for interpretation and change.

A duty to doubt requires careful, painstaking examination of legal issues, the law, and the facts. This carefulness does not mesh neatly with the calls for greater simplicity, efficiency, speed, and certainty, currently demanded by many in law practice today. "[C]ertainty is cheap[;] it is the easiest thing of which a man is capable[]"; ${ }^{98}$ doubt,

96 Paul Carrington likens this concept to what Mark Twain learned in his apprenticeship as a river pilot: "[W]hat [Twain] really learned . . . [was] judgment and courage . . . hardeyed realism and tight mastery of self-doubt. . . [L]awyers like pilots must be always distrustful of themselves, on guard against the risk of mistaking their own political or social preferences for those of the law." Paul D. Carrington, Of Law and the River, $34 \mathrm{~J}$. LEGAL EDUC. 222, 225-26 (1984). What this author might add is that the duty to doubt is most well-suited to guard against poorly reasoned analysis.

97 See Law as Rhetoric, supra note 80, at 684 (discussing the comparable idea of law's nature as a rhetoric constitutive of community).

A word or two about jurisprudential perspectives is in order. This paper does not seek to enter into the debate about the correctness of any particular perspective. However, a view of the practice of law as a process of "doubting" leans against those views that see the law as a set of formal, foundational rules, each with a singular meaning, because, arguably, they are exactly those meanings that are open to doubt. Likewise, a view that sees law as completely subject to the political whim (such as the CLS perspective) might resist doubtful approach because the perspective begins by assuming that there is something to doubt - to question, to explore, and to juxtapose with the lessons of experience, communicative validity, and cultural norms. A jurisprudential perspective that embraces doubt, however, would carve a middle ground and focus instead on having an attitude of skepticism (but not cynicism) and envisioning the law as a confluence of acts, agents, scenes, agencies, and purposes that is neither inalterably fixed nor completely fluid. See also Marouf Hasian, Jr. \& Earl Croasmun, Rhetoric's Revenge: The Prospect of a Critical Legal Rhetoric, 29 PHIL. \& RHETORIC 384 (1996).

98 Kenneth Burke, Counter-Statement 113 (U. Cal. Press 1968) (1931). 
on the other hand, is costly. In other words, the messiness and inefficiencies of doubting one's own conclusions are two of the costs of competence. Lawyers should not be cheap in their thinking or advice. Rather, they should be willing to pay the price, so to speak, for competent advice giving. As discussed in the next section, writing and reading objective memos play an important role in the duty to doubt.

\section{The Meaning of Objectivity}

The basis for good legal advice, such as that contained in a legal memorandum, is essentially an objective assessment, ${ }^{99}$ which might be defined as the ability to take multiple perspectives on the same set of events. In the context of legal judgment, multiple authors have pointed out that objectivity is not about "neutrality."100 Rather, objectivity involves the ability to recognize, understand, and account for differences in perspectives and the values that underlie them. It requires that the writer, who is essentially performing as a critic of the law, the facts, and the way in which the facts intersect with the law, approach the question "with a fair and open mind, with a detached curiosity,"101 all while keeping in mind the lawyer's duty to find the best possible outcomes for the client.

Decades ago, Arthur Miller suggested that "[1]aw, by definition, involves choices made between conflicting values. And writing about law inevitably is colored by valuations. The legal writer is emphatically not a neutral technician."102 Miller's remedy? Miller argued for "conscious instrumentalism," meaning that lawyers "must avowedly and outwardly face up to the questions of values, of goals and purposes, and of alternative ways and means of achieving them." "Only in that way can one be as unbiased and detached as

\footnotetext{
99 See Model Rules of Prof'L CONDUCT R. 2.1 cmt. 1 (2013) (noting that clients are entitled to a lawyer's "honest assessment").

100 See, e.g., Heidi Li Feldman, Objectivity in Legal Judgment, 92 MicH. L. REV. 1187, 1187,1190 (1994) (suggesting that objectivity in legal decision making combines both "description and evaluation" and is suitable for the specific types of judgment needed to make legal decision by taking into account the factors such as shared values and reasoning-giving).

101 Jim A. KUypers, Rhetorical CRiticism: PerspeCtives in ACtion 24 (2009) (discussing rhetorical criticism of texts).

102 Miller, supra note 94, at 303.

103 Id. at 305 .
} 
possible, and only in that way can fairness to the reader be achieved." 104

Miller's description of objectivity as "conscious instrumentalism" as well as the duty to doubt described above, calls attention to how writing and reading the objective memo inextricably intertwines with events, contexts, texts, language, and values. That is, every writer's and reader's liberty to read and write takes place "within a larger field of discursive forces or symbolic practices, the totality of which is indeterminable, yet determining." 105 Accordingly, then, the goal of an "objective" memo writer or reader is to recognize, read, and write within that intersubjectivity - to identify the larger field of symbolic practices that impacts their work.

The intersubjective writing and reading context is rhetorical; every act of giving legal advice is motivated by "a complex of persons, events, objects and relations presenting an actual or potential exigence," which can be resolved by the right discourse. ${ }^{106}$ Moreover, both reader and writer play a significant role in meaning-making in this rhetorical process. By acting within the context, reader and writer have the ability to "produce action or change in the world," 107 to "alter[] reality ... by the creation of discourse which changes reality through the mediation of thought and action." 108 As James Boyd White says, "[u]ltimately, . . . the meaning [of the law is] always arguable, always uncertain .... [Lawyers create a] version of the legal discourse ... in [their] speech and writing." 109 Ultimately, lawyers' choices are constitutive of the law.

In sum, when writing a legal memo, regardless of how that memo is composed and transmitted, the writer has a duty to give competent, independent, and well-informed advice. ${ }^{110}$ This advice is based upon

104 Id. at 302 .

105 BARbara A. Biesecker, AdDressing Postmodernity: KenNETH Burke, RHETORIC, AND A THEORY OF SOCIAL CHANGE 75 (2000); see also Law as Rhetoric, supra note 80, at 691 (noting rhetoric is communal, taking place in a community, and constitutive of that community).

106 Bitzer, supra note 20, at 6 .

107 Id. at 4 .

108 Id.

109 Law as Rhetoric, supra note 80, at 689-90.

110 See MOdEL RULES OF PROF'L CONDUCT R. 1.1. \& 1.2 (2013); see also RESTATEMENT (THIRD) OF THE LAW GOVERNING LAWYERS $§ 46 \mathrm{cmt}$. c ("[L]awyers [need] to be able to set down their thoughts privately in order to assure effective and appropriate representation ....”). 
an objective assessment of the facts and the law, but this assessment is not exterior to the objects evaluated. Instead, legal writers and readers placed within a broad rhetorical context, create and interpret the law and the facts in the rhetorical act of writing and reading a legal memo. To do so competently and effectively requires careful work and recognition of the context in which the lawyer is working. At base, this requires recognition that lawyers have the power to shape the law and that advice giving is a creative act of judgment. Moreover, it requires recognition of how other mental operations can interfere with independent judgment and what strategies may guard against those faulty processes.

\section{Problems with Decision Making}

At the heart of memo writing is the process of decision making. That is, memo writers make decisions about what law is applicable, what facts are meaningful, what arguments are viable, and what advice is appropriate. This section describes how intuition, implicit bias, and fallacious reasoning can negatively impact legal decision making by encouraging the legal writer to hastily and erroneously draw conclusions or ignore evidence or logic that is inconsistent with a preselected conclusion.

Intuition and deliberation are commonly accepted models of cognition, and they impact decision making. ${ }^{111}$ The difference between intuitive and deliberative decision making has been described as the difference between "blinking" and "staring" at a problem. ${ }^{112}$ In other words, the level of effort, length of time, and use of reasoning skills distinguish intuitive and deliberative processes. Intuitive decision making is generally described as associative, automatic and effortless, and often subject to emotional influences. ${ }^{113}$ "Intuitive thought processes occur spontaneously and involve decisions that are made automatically, effortlessly, and quickly."114

111 See, e.g., Chris Guthrie et al., Blinking on the Bench: How Judges Decide Cases, 93 CORNELL L. REV. 1, 6-13 (2007) (describing the differences between intuition and deliberation); see also John F. Irwin \& Daniel L. Real, Unconscious Influences on Judicial Decision-Making: The Illusion of Objectivity, 42 MCGEORGE L. REV. 1, 2 (2010).

112 Irwin \& Real, supra note 111 , at 2 (describing intuitive decision making as "blinking" decisions such as "quick, heat-of trial decisions" and deliberative decision making as "staring" such as "carefully considered and weighed decisions").

113 Id. at 5.

114 Id. 
Intuitive decisions are "based on quick impressions made without time to fully evaluate all potential influences and ramifications." 115

Deliberative decisions, on the other hand, are "mental operations requiring effort, motivation, concentration, and the execution of learned rules." 116 They are "deliberate, rule-governed, effortful, and slow." "Deliberative thought processes . . . occur through controlled processing and involve decisions that are rule-governed and made slowly with great effort." 118 "[D] eliberative decisions are based on carefully weighing available options and factors, and are reached after the passage of time and careful consideration." 119

Intuitive decision making is appealing to decision making in the context of high-tech legal practice, because it has the advantage of speed. This appeal can tempt lawyers to use intuition as the primary decision-making tool. Although useful in some contexts when utilized by expert decision makers, ${ }^{120}$ intuitive decision making can lead legal reasoning astray unless carefully balanced with deliberative decision making. ${ }^{121}$ In other words, if lawyers use only intuitive decisionmaking techniques, lawyers may fail to meet their duty to evaluate a situation competently because of the intuitive decision-making tendency for instantaneous conclusions without reflection. ${ }^{122}$

Intuitive decision making is problematic in part because of its relationship to implicit bias-"unconscious or subconscious influences on decision making"123 - and fallacious reasoning. Both of these make it easier to reach conclusions without careful attention to

\footnotetext{
$115 \mathrm{Id}$. at 7.

116 Guthrie et al., supra note 111 , at 7.

117 Id. at 8.

118 Irwin \& Real, supra note 111, at 5.

119 Id. at 7.

120 See Berger, supra note 16, at 275 (describing the value of intuition by judges who are experts in judicial decision making); Guthrie et al., supra note 111, at 30-32 (noting that "[t]he conversion of deliberative judgment into intuitive judgment might be the hallmark of expertise" but it is reliable only after "years of 'effortful study' as well as accurate and reliable feedback on earlier judgments").

121 Guthrie et al., supra note 111, at 5 n.20 (explaining that "for most people," managing deliberation and intuition means "more active use of the deliberative system").

$122 \mathrm{Id}$. at 33 (suggesting the use of "deliberation as a verification mechanism").

123 Irwin \& Real, supra note 111, at 2-3 (discussing concept of implicit bias in judicial decision making and defining implicit bias as "unconscious mental processes based on implicit attitudes or implicit stereotypes which play an often unnoticed role in day to day decision-making").
} 
the difficult reasoning processes or the uncomfortable condition of wrestling with uncertainty.

One type of implicit bias is "belief bias" a bias which directly impacts the syllogistic reasoning process. ${ }^{124}$ Belief bias is "[t]he tendency to accept or reject a conclusion on the basis of its consistency with everyday knowledge, regardless of its logical status." "125 Belief bias is particularly dangerous to legal analysis because it can impact one's ability to recognize faulty reasoning and deal productively with uncertainty. In one study of belief bias, participants examined a syllogism that was consistent with everyday experience, but invalid. Despite the invalidity, ninety-two percent of participates endorsed the conclusion as valid. ${ }^{126}$ Conversely, only eight percent of participants endorsed a valid syllogism when it was not consistent with everyday experience. ${ }^{127}$

In addition, some research suggests that belief bias is the result of the cognitive error of "misinterpreted necessity," which is a process of "belief-based responding as an escape-hatch mechanism when deductive reasoning is inconclusive." 128 In other words, when rulebased reasoning does not yield a certain result, individuals tend to fall back upon their beliefs - rather than their reasoning skills - to come to a conclusion.

Belief bias may also be explained in part by selective scrutiny. Selective scrutiny is the process by which individuals jump to conclusions that reinforce their beliefs and overlook the reasoning behind those conclusions. ${ }^{129}$ Selective scrutiny results from "subjects focus[ing] initially on the conclusions of the arguments and accept[ing] believable conclusions without any evaluation of their logical validity." 130 And, even when individuals are confronted with evidence contradictory to their beliefs, cognitive dissonance theory suggests that they are more likely to try to convince and convert others to their view rather than change their own position. ${ }^{131}$ Relatedly, confirmation bias is the tendency of individuals to interpret

\footnotetext{
124 Chad Dube et al., Assessing the Belief Bias Effect with ROCs: It's a Response Bias Effect, 117 PSYCHOL. R. 831, 831 (2010).

125 Id.

126 Id. at 832 .

127 Id.

$128 \mathrm{Id}$. at 833 .

129 Id.

$130 \mathrm{Id}$

131 McElroy \& Coughlin, supra note 94, at 232.
} 
and remember information in a way that confirms their point of view, which results in individuals observing what they expect in situations. ${ }^{132}$

In addition to biases that result in poorly reasoned and hasty conclusions, other biases result in individuals who are engaged in decision making, ignoring important aspects of a problem. Coherence based reasoning theory suggests that individuals will take complex situations requiring a decision and transform these situations into a "straightforward choice between a compelling alternative and a weak one." 133 These individuals tend to create "representations in which the variables that support the emerging decision are strongly accepted while those that support the losing decision are dismissed, rejected, or ignored." ${ }^{134}$ The fallacy of selective attention is related; individuals commit this fallacy of reasoning when they improperly focus on some aspects of an issue while ignoring others. ${ }^{135}$

Intuitive decision making and cognitive biases have been recognized as dangerous to the legal decision-making process, particularly where the decision maker, such as a judge, needs to make a clear, and well-reasoned decision. For example, Chris Guthrie, Jeffrey Rachlinski, and Andrew Wistrich conclude that intuition can be dangerous because it can "lead judges astray." 136 John Irwin and Daniel Real similarly conclude that implicit biases can have "potentially significant ramifications in judicial decision-making.,"137

In sum, intuitive decision making, cognitive bias, and related logical reasoning fallacies make it possible for lawyers to avoid the tedious, rigorous process of reasoning through legal problems. From the beginning, the objective legal memorandum was designed to deal with these inherent limitations on critical thinking, decision making, and advice giving by demanding reflection and deliberation as a

132 See Margit E. OSwald \& Stefan Grosjean, Confirmation Bias, in Cognitive ILLUSIONS: A HANDBOOK ON FALLACIES AND BIASES IN THINKING, JUDGMENT AND MEMORY 79, 79 (Rüdiger F. Pohl, ed., 2004).

133 McElroy \& Coughlin, supra note 94, at 231-32.

134 Id. at 232.

135 Bradley Dowden, Fallacies, INTERnET ENCYCLOPEDIA OF PHIL., http://www.iep .utm.edu/fallacy/\#Selective\%20Attention (open access, peer edited resource hosted by University of Tennessee) ("The pessimist who pays attention to all the bad news and ignores the good news thereby commits the fallacy of selective attention. The remedy for this fallacy is to pay attention to all the relevant evidence.").

136 Guthrie et al., supra note 111, at 5.

137 Irwin \& Real, supra note 111, at 2. 
balance to intuition and as a foil for bias. ${ }^{138}$ In addition, the process of writing itself is an effective mechanism for dealing with the shortcomings of intuition and the dangers of bias in legal analysis. The following two sections explore the history of the legal memorandum and provide an assessment of how structured writing impacts competent advice giving. This history and assessment demonstrates that writing comprehensive - not summarizing or informal-legal memos is as important as ever for rendering competent legal advice.

\section{Traditional Solutions to Modern Cognition Problems: The History of the Legal Memo}

The memo has a rich but relatively recent history in legal writing. While the ability of law schools to teach legal skills, such as writing, had been questioned since law school's inception in the mid-1800s, ${ }^{139}$ the first references to legal writing as a separate subject matter, apart from bibliographic instruction, appeared in the late 1940s. ${ }^{140}$ One of the first bar journal articles about legal memo writing appeared in 1956. ${ }^{141}$ The author was Frederick vom Baur, Harvard Law graduate,

138 Arguably, the writers of this early literature did not have the benefit of the extensive research that has now emerged regarding critical thinking, decision making, and advice giving. Some of that history was written even before the ABA had adopted a modern code of professional responsibility that made competence an express ethical duty of lawyering. Yet, in responding to the need for newer lawyers in particular to think through and communicate about legal problems, the early design of objective memos remains as relevant as ever. See infra Part II.A.4.

139 Robert SteVens, LAW SChoOl: Legal Education in AMERICA from the 1850S TO THE 1980 S, at 214 (1983).

140 Legal writing first appeared as a category in the AALS in 1947. See Kathleen M. Carrick \& Donald J. Dunn, Legal Writing: An Evaluation of the Textbook Literature, 30 N.Y.L. SCH. L. REV. 645, 647 (1985). Prior to that, law school courses focused on bibliographic research instruction that included "writing experience" and also had "remedial objectives related to deficiencies in legal education perceived during the postWorld-War II ferment." Marjorie D. Rombauer, First-Year Legal Research and Writing: Then and Now, 25 J. LEGAL EDUC. 538, 539 (1972). Rombauer recognized one book published in 1906 that included instruction on brief writing, but in 1923, a competitor text on bibliographic instruction concluded that legal writing was "inappropriate for first-year instruction." Id. Writing in the "70s, Rombauer notes that the latter view had "apparently prevailed." Id.

141 vom Baur, supra note 4 , at 28 . This was later reprinted in book format. See F. Trowbridge Vom Baur, THE Practical LaWyer's ManUal on MEMORANDA OF LAW (ALI-ABA 1970) [hereinafter MANUAL]. A brief reference to memo writing appeared in 1953 in a book written by a University of Michigan law professor. He notes that " $[t]$ he law graduate who begins his practice in a large office will often find that much of his work consists of preparing law memoranda for use of the senior partners (and he will find, also, that his work is judged in large part on his ability to prepare an easily read, 
previous General Counsel to the Navy, and senior partner at a D.C. Law Firm. ${ }^{142}$ He wrote about the purpose and structure of the legal memo. He attributed the origins of the legal memo to law firms in the "big cities," which, "through strenuous effort and trial and error, [had developed] effective systems for looking up law and writing legal memoranda, economically and at their optimum."143 Vom Baur placed great value on writing legal memoranda because of their role in legal problem solving and legal advice giving. In his manual on memo writing that was published in 1970, vom Baur offered that

legal research and memoranda of law are important-to put it mildly - because they are the fundamentals that underlie good legal advice and good legal opinions. Indeed, the more complicated or important the problem, the greater the need for a first-rate memorandum of law ... The interests at stake are too important to compromise with mediocrity. . . . [W] available, there is seldom a real reason to make such a compromise. $^{144}$

The structure vom Baur described would appear quite familiar to today's legal writer: he suggested that the objective memo sections include facts, question presented, short answer or summary, and discussion. ${ }^{145}$

Importantly, vom Baur linked competence, good advice giving, careful reasoning, deliberation, and the development of legal skills to writing legal memoranda, contrasting the "slopping-along" of instinctive decision making ${ }^{146}$ :

It should be brilliantly clear to the law student and the young graduate that looking up law and writing legal memoranda is a subject of basic and far reaching importance. For, by his experience in this area, he either learns to think and act like a lawyer in full accord with standards of thoroughness, precision, and judgment, or he drifts into a kind of slopping-along process, playing by instinct, sometimes right and sometimes not. Moreover, if the writer's experience is any criterion, competence in legal research and writing legal memoranda should be of concern to the lawyer of any age in his day-to-day work. For, such competence will provide good

accurate, useful memorandum)." FrANK E. COOPER, EFFECTIVE LEGAL Writing 2 (1953).

142 MANUAL, supra note 141 , at v-vi.

143 Id. at 2.

144 Id.

$145 \mathrm{Id}$. at 38 .

146 vom Baur, supra note 4, at 43 . 
legal answers with a minimum of expenditure of time and, thus, serve as a measure of gain, professionally and financially. ${ }^{147}$

It cannot be overstated how closely vom Baur tied the legal memo to good advice giving; "poor legal research or a poor memorandum of law will eventually put the client on one course," vom Baur noted, "while better research and a better memorandum on the same subject may put the client on a safer, wiser and different course and save him money. At the very least, it will put him on a course which has solid effort and thinking behind it." 148 Others joined vom Baur in the link he made between the legal memo and good legal advice. One writer noted that "[t]he importance of help and advice from the law office can hardly be overstressed . . . . The law is complex, and the dispensing of legal advice is an art not easily acquired."149 Further, they recognized that a memo "requires concrete advice. It is up to the associate to come up with the answer to a question and to give the reasons backing that answer in terms of advocacy so that his position can be defended." 150

Although the practicing bar recognized the importance of the objective memorandum beginning in the 1950 s, the first significant law school text that included instruction on the objective memo did not appear until $1970 .{ }^{151}$ This text was written by well-known legal writing professor, Marjorie Rombauer. ${ }^{152}$ She defined the legal memorandum as a form of "objective writing," which she described as writing that critically analyzes and discusses a problem and is meant to be "exploratory, unaffected by personal goals or desires." Rombauer distinguished memo writing, a form of "practice writing," from "advisory writing." 154 In her view, practice writing "is directed toward analyzing a particular legal problem for the purpose of predicting a probable solution or stating the basis for suggested advice." Alternatively, advisory writing, which includes client letters,

\footnotetext{
147 Id.

$148 \mathrm{Id}$. at 28 (noting that "legal [m]emoranda [is a] fundamental that underlies legal advice").

149 Theodore Voorhees, Legal Research and Memoranda, 36 N.Y. ST. B.J. 222, 227 (1964).

$150 \mathrm{Id}$; see also vom Baur, supra note 4, at 29 (noting that a goal of the memorandum is to persuade the reader that the basis for the conclusions in the memo are "sound").

151 MARJORIE DiCK ROMBAUER, LEGAL ANALYSIS AND RESEARCH (1970).

152 See Mary S. Lawrence, An Interview with Marjorie Rombauer, 9 J. LEG. WRITING INST. 19 (2001) (discussing Rombauer and her contributions to legal writing).

153 ROMBAUER, supra note 151, at 111.

154 Id.
} 
"informs [readers] of conclusions and the reasons therefor and gives advice." 155

Rombauer's distinction between practice writing and advisory writing is important to the discussion of the current rhetorical situation for objective memo writing. That is, other lawyers are meant to be the audience for the objective legal memorandum whereas clients are not. In the event the audience of document is a client, then the objective memo, traditional or otherwise, is not the correct document for the situation because a document transmitted to a client is addressed to a different rhetorical situation. In preserving the effectiveness of the objective memorandum, the audiences-lawyers and clients - cannot be conflated. If a document is meant to serve a client, that document should have properties different from those of an objective memorandum. ${ }^{156}$

Rombauer also identified memo writing as the cure for "fail[ing] to analyze objectively" even before the application of cognitive psychology to legal decision making. ${ }^{157}$ Rombauer explained that "[t]he purpose of a memorandum is to explore the strength of your opponent's case as well as the strength of your client's case."158 "You should therefore discuss fully any authorities contrary to your client's position as well as those favoring his position .... [D]o not lay a trap for your reader by failing to point out the weaknesses of the arguments you build." "159

As discussed above, maintaining the objectivity needed for competent advice giving in the face of biases and weaknesses in reasoning is challenging. Vom Baur and Rombauer recognized this early in the development of legal memo writing. Today, cognitive psychology research and theory demonstrate that the same objectivity problems vom Baur and Rombauer wrote about a half-century ago

\footnotetext{
155 Id.

156 Some lawyers, in fact, would send an objective memorandum directly to a client, particularly when that client is another lawyer. See, e.g., The Memo is Dead, supra note 9, at 6 (noting that lawyers report sending memoranda to clients). The important point for this Article is that, when originally conceived, the objective memo was meant to be a communication between lawyers as representatives of a client, not between lawyer and client. Certainly, lawyer-clients, such as in-house counsel, present a unique rhetorical situation. This author suggests that the lawyer-advocate should treat that lawyer-client more as lawyer and less as client for the purposes of the objective memo and send a more analytically detailed memorandum consistent with the strategies described in this Article.

157 ROMBAUER, supra note 151, at 118.

158 Id.

159 Id.
} 
persist. The next section discusses how the act of writing within the memo structure makes a positive difference in ensuring that objectivity and careful thinking are preserved in advice giving.

\section{Writing, Structure, and Competent Advice Giving}

The act of writing the legal memorandum for the purpose of constructing legal advice helps the author engage in deliberation instead of intuition, make reasoning apparent, and avoid the problems of implicit bias and faulty reasoning. First, "[w]riting separates the known from the knower. It promotes "objectivity." 160 In other words, writing allows for the kind of complex logic and reasoning that oral expression does not. ${ }^{161}$ Moreover, writing promotes the kind of intersubjectivity that solves problems. By allowing the writer to explore problems in depth and preserve them on paper, writing allows for new identifications and linkages at a level of precision that oral expression cannot approximate. ${ }^{162}$ In other words, the act of writing allows the writer to construct a motivation ${ }^{163}$ for the legal analysis that might not be apparent in the law or facts themselves.

Second, memo writing can force deliberation when intuition might be the default and can impose a logical structure to reasoning when that structure might otherwise be lost. Irwin and Real identify ways to compensate for the implicit biases that affect objectivity. One way is through writing, which can "induc[e] . . more effective deliberative thought processing." 164 In fact, in their work on judicial decision making, Irwin and Real suggest that deliberation by judges can be improved by increasing the "frequency with which judges . . . issue

\footnotetext{
160 Ong, supra note 14 , at 24 . Ong further writes that "[b]etween knower and known writing interposes a visible and tangible object, the text. The objectivity of the text helps impose objectivity on what the text refers to." Id. at 25.

$161 \mathrm{Id}$. ("Whereas oral cultures tend to merge interpretation of data with the data themselves, writing separates interpretation from data.").

$162 \mathrm{Id}$. at 28 (explaining that writing is central to linear, logical explanations and that "elaborate explanatory thinking depends upon writing and the revisionary, back-tracking operations made possible by [it]").

163 For the well-known rhetorician Kenneth Burke, what distinguishes us as human is our ability to engage in purposeful action, or to be motivated. See generally KENNETH Burke, A Grammar of Motives (1945); KenNeth Burke, A RHETORIC OF Motives (1950). That is, language does not simply reflect our motivation, it constructs motivation; "our words define us . . . our identities are but composites of our symbol system." DAVID BLAKESLEY, THE ELEMENTS OF DRAMATISM 6 (2001) (discussing the work of Kenneth Burke)

164 Irwin \& Real, supra note 111, at 8; see also Guthrie et al., supra note 111, at 36-37 (arguing that if judges wrote more opinions, it "could induce deliberations that otherwise would not occur").
} 
written decisions explaining the rationale supporting the decision."165 Likewise, a written objective memorandum can serve as a device for both analytical clarity and explanation, and it can help a legal writer avoid the shortcuts in reasoning that result from failing to carefully walk through a legal analysis, from collecting and organizing the facts to defining the legal questions to analyzing competing outcomes.

Third, memorandum writing permits the invention of the negative. In the context of memo writing, this means the writing has the ability to construct multiple perspectives and explore all sides of a legal question. Kenneth Burke, a well-known rhetorical scholar, defined humans in part by their ability to invent the negative. ${ }^{166}$ This ability to invent the negative through language gives language a moralizing function. ${ }^{167}$ That is, language is able to describe not only what "is" but also what is "not." For example, in nature, a tree is a tree and a shrub is a shrub. But, with language, a tree can be "not a shrub." In other words, the negative is a purely linguistic resource of human creation. ${ }^{168}$ This ability to invent the negative through language makes humans capable of moral or ethical action, to not only make decisions about the existence of different options in the material world, but also to assess the value of them.

This ability to invent the negative through language is central to the lawyer's duty to doubt and thus, is central to the memo-writing task. ${ }^{169}$ At the core of advice giving lies the duty to doubt the first and most obvious answer - to be skeptical, inventive, and insightful. In the memo writing process, the duty to doubt can be most fully expressed in the invention and exploration of counterarguments.

\footnotetext{
165 Irwin \& Real, supra note 111 , at 9.

166 Kenneth Burke identified the ability to engage in "invent[ion] of the negative" as an essential quality of humanness. KENNETH BURKE, LANGUAGE AS SYMBOLIC ACTION: ESSAYS ON LIFE, LITERATURE, AND METHOD 16 (1966). Burke defined humans through a rhetorical lens: "Man is the symbol-using (symbol-making, symbol-misusing) animal, inventor of the negative (or moralized by the negative), separated from his natural condition by instruments of his own making, goaded by the spirit of hierarchy (or moved by the sense of order), and rotten with perfection." Id.

167 Id.

168 Id. at 9.

169 Interestingly, Burke notes that "[1] aws are essentially negative" and are examples of the moralizing negative he imagines. $I d$. at 11 . He specifically mentions property law as an example of "mine" and "not thine" that becomes the basis of our communal "character." Id. See also Francis J. Mootz, Rhetorical Knowledge in Legal Practice and Theory, $6 \mathrm{~S}$. CAL. INTERDISC. L. J. 491, 577 (1998) (noting that "the activity of invention is the critical element of legal practice").
} 
Invention is used intentionally here, because the writer invents the negative by asking this question: what if the first analysis is not the best analysis? Through the process of step-by-step analytical writing, the writer can explore those negatives fully.

Fourth, the structure of the comprehensive objective memorandum provides a "disciplining effect" biases and shortcomings in reasoning. Years ago, Rombauer suggested that legal memo writers always use what she called the "comprehensive" form-a form that included a question presented, brief answer, facts, discussion, and conclusion. ${ }^{171}$ Rombauer found that "[the] comprehensive form is recommended because it will lead you to do the kind of careful and comprehensive analysis that is always necessary, even if the required memorandum is to be only a two-page outline." 172 In other words, Rombauer suggests that the objective memorandum is so important to the thinking and reasoning process that writing a memo was not contingent upon what the reader ultimately read or desired.

Structures, like the structure provided in comprehensive objective memoranda, encourage deliberative thinking and, accordingly, competence. ${ }^{173}$ A particular structure for writing can have a "forcing function" that encourages deliberative thinking. Forcing functions are important because they "mitigat[e] cognitive error by nudging [writers] . . . toward more deliberative processes." "In the most extreme, these forcing functions "are exemplified by computer systems that force the user to complete step[s sequentially]." 175 Forcing functions prevent users from acting without conscious consideration of information. By requiring conscious step-by-step consideration, these functions deliberately disrupt the unconscious performance of a task. ${ }^{176}$

170 See Guthrie et al., supra note 111 , at 35 (mentioning the "potential disciplining effect of opinion writing").

171 RoMBAUER, supra note 151, at 112-15.

172 Id. at 112

173 A structure like the one referred to here is sometimes identified as a "heuristic device." A heuristic device is "[a]ny procedure which involves the use of an artificial construct to assist in the exploration of social phenomena .... [It is] a form of preliminary analysis ... [that] is usually employed for analytical clarity, although it can also have explanatory value as a model." GORDON MARSHALL, A DICTIONARY OF SOCIOLOGY 274 (2d ed. 1998).

174 Guthrie et al., supra note 111 , at 41 .

175 Id. at 42.

176 Id. at 42 n.207. The concept of a "forcing function" comes from computer systems design where it is used to define an "aspect of design that prevents the user from taking an 
Guthrie, Rachlinski, and Wistrich describe how writing in a particular structure can have a disciplining effect on legal reasoning. ${ }^{177}$ In the context of judicial writing, they suggest that "[r]ather than serving merely to describe an allegedly deliberative process that has already occurred . . . the discipline of opinion writing might enable well-meaning judges to overcome their intuitive, impressionistic reactions. The process of writing might challenge the judge to assess a decision more carefully, logically, and deductively." ${ }^{178}$ Moreover, they argue for the use of different types of "forcing" structures - of "scripts, checklists, and multifactor tests"that would "encourage [judges] to proceed methodically, thereby ensuring that they touch all of the deliberative bases." 179 They note that "a [j]udge who must review a script or checklist at each step in the decision-making process is less likely to rely on intuition when doing so is inadvisable." 180

Writing legal memoranda using the comprehensive form (i.e., question presented, brief answer, facts, discussion, conclusion) is the implementation of a forcing function; it is a disciplining structure that can be the cure for the biases of intuitive decision making. In addition, although some on-screen legal readers might think that brevity should be the priority for on-screen documents, common sense suggests that legal readers do not prioritize brevity over a complete and soundly-reasoned legal analysis. ${ }^{181}$ Accordingly, completeness and analytical thoroughness should be the fundamental touchstones for evaluating the effectiveness of an objective memorandum, whether that memo is read on-screen or off.

Moreover, legal readers want to see the premises underlying legal reasoning. "[O]nly when the premises are stated explicitly is it

action without consciously considering information relevant to that action. It forces conscious attention upon something ... and thus deliberately disrupts the efficient or automatised [sic] performance of a task ....."Id. (quoting Mads Soegaard, Forcing Functions, INTERACTIVE DESIGN FOUND., http://www.interaction-design.org/encyclopedia /forcing_functions.html (last visited Sept. 25, 2007)). See also Ong, supra note 14, at 23 (noting that "writing raises consciousness").

177 Guthrie et al., supra note 111, at 38-41.

178 Id. at 37.

$179 \mathrm{Id}$. at 40.

180 Id.

181 See Posting of Sarah Ricks, to Legal Writing Institute Listserv posting (July 18, 2005) (on file with the author) (noting that "while the e-mail format may appear less formal, the rigor of the analysis should be the same, whether or not the analysis is in electronic form"). 
possible to determine how valid the conclusions are."182 In other words, it seems unlikely that a lawyer who has asked another lawyer to analyze a legal question would want to see conclusions rather than the premises that support those conclusions, even if those premises were necessarily lengthy and needed to be read on the screen. Accordingly, if a legal reader ultimately wants precision and thoroughness, the reader wants a writer to use the forcing function of the comprehensive legal memorandum, regardless of whether the document is meant to be read on or off screen.

Finally, the act of writing the legal memo is important because it creates an opportunity for the legal reader to reflect upon what is written. Without preserving legal analysis in writing, the audience lacks the same opportunity to consider and question the analysis. Reading is a form of engagement between writer and reader; the memo itself is a place for the reader to engage in invention, to assess what is written and to add to it, question it, or revise it. Reading a memo is a creative act; "[s]ince knowledge cannot be physically transferred verbally from one human person to another but must always be created by the hearer or reader within his or her own consciousness, interpretation always plays a role when one ... reads." 183 Additionally, while the interchange between lawyer and client might not require that the text enable the client to question the premises of the analysis, certainly, communications between lawyers need sufficient explanation of reasoning to exercise the duty to doubt.

In sum, carefully structured objective analysis in a legal memorandum enhances objectivity and strengthens logical thinking. The structure of a legal memorandum (i.e., question presented, brief answer, facts, discussion, conclusion) and the logical structure of the written analysis (i.e., rule synthesis, case description, and analysis of facts) provide the writer with a structure that can help to "force" deliberative decision making and analysis. Writing an objective memo encourages the writer to fully engage with the resources of legal creativity and invent the negative sufficient to satisfy a skeptical reader and yield competent advice. In turn, the reader can repeatedly engage the written word, inventing his or her own assessment of the objectivity of the analysis. The acts of objective writing and reading are critical to competent advice giving. As both vom Baur and Rombauer wrote decades ago, the more carefully written and

182 Miller, supra note 94, at 303.

183 Ong, supra note 14, at 25. 
structured a legal memorandum, the more sound the underlying legal advice. And nothing, not even on-screen reading, suggests that writing itself is any less important to legal thought than it was then.

What has changed is the media on which lawyers read and write legal memos. Does the use of electronic media require a new approach to the substance or form of the legal memo? Are electronically delivered memos a new category of legal writing? The next section dispels the myth of this category change and argues that the traditional approaches to memo writing are exactly what legal readers need for reading legal memos on new media.

\section{B. “On-Screen" Is Not a New Legal Memo Category}

Without a doubt, lawyers read on a screen. But, this new form of reading does not create a new legal memorandum category. ${ }^{184}$ Rather, new media requires that lawyers pay even more attention to the historically recognized flexibility of the legal memorandum form. In other words, "conveying legal analyses in e-mail correspondence is simply a technologically spurred extension of long standing diversity in law office communications." 185 Accordingly, this section explores the flexibility in the legal memo's structure and why that structure can effectively communicate analysis in an "on-screen" legal memo. Moreover, to the extent that on-screen reading of legal memoranda is different, this section describes why traditional writing structures are particularly well-suited to that environment.

The "traditional" memo has been criticized as being not sufficiently flexible to meet the needs of an "on screen" legal reader. ${ }^{186}$ In particular, Tiscione characterized the traditional

\footnotetext{
184 Margolis, supra note 11, at 124 (noting her thoughts that "this kind of ecommunication called for a different kind of writing than is traditionally covered in a legal research and writing course").

185 Charles Calleros, (Still) Teaching Traditional Office Memoranda in an Age of Email Memos, handout 11th Annual Rocky Mt. Legal Writing Conference, University of Nevada Las Vegas (Mar. 26, 2011) (on file with the author).

186 What can we safely say, in general terms, about legal readers? Three characteristics come to the fore: (1) They are frightfully busy and therefore impatient. (2) They are hopeful for something useful in their work, but they are easily disappointed. (3) They are professionally skeptical and, by nature, uncharitable. They are skeptical because they have been trained to think of contrary views, and they know the argumentative strategies for doing so. They are uncharitable because they believe that accuracy with pertinent details typifies accuracy in other matters - that if the details are not right, there is little reason to think that the larger points will be right.
} 
objective memo as "static" as opposed to the "informal" memo and "substantive" e-mail, which are more "organic."187 This characterization of the traditional memo, however, misses its perennial and intentional flexibility. While a memorandum written in the "comprehensive" style is arguably best for legal thinking, it is the complexity of the question presented, and not the type of media that should dictate the structure of the memo.

The organic and flexible nature of the memo has long been recognized. Importantly, this flexibility was contingent upon the nature of the problem facing the legal writer and reader. For example, in 1964, one author writing about legal memoranda noted that "an experienced lawyer may encompass in a legal memorandum of a page or two all that need be said in answer to a simple problem. He may not need to divide and sub-divide the topics, nor over-refine the issue." 188 Moreover, even after she recommended the comprehensive form for "careful and comprehensive analysis," Rombauer noted that

[a]cceptable memorandum format varies from office to office and from problem to problem. In some offices, and particularly for a simple question, a one-or two-page outline of controlling rules with citation of supporting authorities may be all that is required. Other offices require a highly stylized format. Some require that a brief be attached for every cited case ....

Ultimately, the objective memo itself has sufficient flexibility, within its existing structure, to meet the needs of the on-screen reader. But that flexibility should relate to the nature of the question asked, not the nature of the media. For example, if a lawyer asks for a memo that describes a statute of limitations, without reference to any specific facts, that memo will be decidedly short. Similarly, a memo may call solely for an analysis of law without reference to specific client facts. In that case, a facts section would be inappropriate. However, where the facts are complex and the law is in dispute, the memo would necessarily be longer by virtue of a facts section and

BRYAN A. GARNER, Know thy Reader: Writing for the Legal Audience, 38 STUDENT LAW. 12, 12 (Sept. 2009). Garner's comments show that even though we might think technology has changed legal readers, the qualities of legal readers-impatient, easily disappointed, and skeptical - are all perennial legal reader qualities. In other words, it may be that little has changed about the legal readers other than the technology they use- screens rather than paper-for reading.

187 Snail Mail, supra note 12, at 33 (assessing legal memoranda in light of her survey participants" view of the memo as "dead").

188 Voorhees, supra note 149, at 225.

189 ROMBAUER, supra note 151 , at 112 . 
fact analysis. The writer would need to explain to the reader the possible outcomes and arguments. Because these memos are read onscreen does not change the necessary substance of the underlying document.

Misinterpreting the traditional legal memo as inflexible and identifying "e-mail memos" as a separate category of writing, endangers the quality of memo writing. First, identifying electronically delivered memoranda as a new category overlooks the adaptability of the legal memo form to effectively address a range of legal analyses that will be read on a variety of media. Furthermore, separating out on-screen memos as a new category conflates the choices that one must make regarding how to render a complete and competent legal analysis with choices that a writer might make to assist the legal reader in reading on the screen.

Margolis's recent article identifies the way in which naming the "email memo" as a new memo category is dangerous, particularly when dealing with novice legal writers. ${ }^{190}$ In that article, Margolis described how she directed first-year law students to complete "an email summary of their analysis." 191 By specifically requesting a summary, Margolis recognized the difference between this assignment and a traditional memo assignment. ${ }^{192}$ This is an important distinction; while a summary may be a different and useful type of legal writing, a summary is not a legal memorandum. By definition, a summary lacks the depth and precision necessary to qualify as a memo. Thus, while summarizing may be a legal writing technique - both on-screen and in-print-summarizing is not unique to the on-screen environment and is not a type of legal memorandum.

Margolis noted what she deemed to be two positives about the email "summarizing" activity that, when considered in light of a legal memorandum's purpose, are arguably negatives. First, she noticed that "[e]ven students who were weaker analytically, or who had difficulty with writing clear, direct prose, did a very good job summarizing their analyses in the electronic context."193 This point is critical, but arguably not for the reason Margolis suggests. Rather, the critical point is that the clarity of the prose and the absence of analytical weakness are arguably not the result of writing in the

\footnotetext{
190 See generally Margolis, supra note 11.

191 Id. at 124 .

192 Id.

193 Id.
} 
electronic context; rather, they are a result of not being required to write a carefully constructed, analytically transparent memorandum and instead being asked to write a summary. Accordingly, the idea that a new category of legal memo exists because readers are looking for "short," "summarizing," or "brief" legal memos can result in readers getting what they may say they want but not what they actually need. In other words, a legal memorandum, whether electronic or not, is not a summary.

Second, Margolis noted that student writers liked the "lack of preexisting structure" provided by the e-mail memo/summary assignment. ${ }^{194}$ Arguably, students liked this assignment because it lacked the "forcing function" of the comprehensive legal memorandum. That is, students were not required to go methodically, step-by-step through the labor demanded by a comprehensive legal memo. Rather, they were able to avoid that hard work by choosing a form that "summarized," or, in other terms, perhaps, "superficialized" the analysis.

In sum, there is no unique category of objective legal memoranda based upon the advent of new technology. Rather, the comprehensive legal memorandum is flexible enough to satisfactorily handle both simple and complex legal questions, whether in traditional print or on electronic media. Just as the printing press enlarged the means by which legal analysis was communicated (as opposed to orally or through scribes), electronic communication devices expand the modes of transmission. Simply being on-screen, however, does not change the memo's fundamental nature; legal memoranda still serve the same purpose as they traditionally served-to clearly communicate thorough analysis for the purpose of giving advice - and they should be structured to do so.

Importantly, how readers read on the screen presents a different question. And legal writers should be concerned about how the constraints of electronic mediums affect how they write memoranda. The next section will address that concern.

$194 \mathrm{Id}$. This is not to say, however, that novices do not recognize the importance of overall structure. Margolis noted that in a different e-mail memo assignment, students observed "how important organization was" to the e-mail memo. Id. at 123. 


\section{Inviting Legal Readers to "Stare" at the Screen: Traditional Organizational Strategies and On-Screen Reading}

The shift to on-screen reading has caused some commentators to suggest that some legal writing is inappropriate for the screen. As previously described, some legal writing texts suggest that "e-mail memos" should not fill more than one computer screen, should not be longer than one to three pages, or should not be longer than a page. ${ }^{195}$ In addition, they suggest that e-mail is not the correct medium for a memo traditionally provided in hard copy ${ }^{196}$ and, conversely, should be short enough to be easily accessible "through any hand-held device." 197

These limitations on using the screen for reading legal memos ignore the realities of today's legal practice, however. That is, all legal reading is rapidly moving to on-screen legal reading. ${ }^{198}$ So what, then, should be done about this, from the legal writer's perspective? This section takes up this question and suggests that these new mediums call for a renewed commitment to deliberative writing and intentional "formal" text structures. Complex analysis in an e-mail can be read on a screen if that analysis is well structured. Any document of any length should be navigable on-screen. In other words, many lawyers are going to read on the screen rather than on paper. The question is, how should legal writers approach that task?

This section first discusses research about on-screen reading. It then turns to a discussion of text structures and how the structure of the legal memo facilitates reader comprehension on-screen. Finally, it discusses structural features lawyers should use when writing legal memoranda for an on-screen reader.

\section{Reading on the Screen}

Arguably, all people, including lawyers, read differently when they read from a screen than when they read from print on paper, and that difference may result in speed and cognition differences. ${ }^{199}$ A number

195 See supra Part II.D.

196 Margolis, supra note 11, at 123.

197 Id.

198 See supra Part II.B.

199 See Anne Mangen, Hypertext Fiction Reading: Haptics and Immersion, 31 J. RES. READING 404, 404 (2008) ("Theorists across disciplinary boundaries largely agree that we read differently when reading digital texts, compared with reading print. Moreover, not 
of factors have been studied to account for this altered on-screen reading style, particularly those that impact reading on a mobile device. The nature of the on-screen documents (either hypertext or "long form," linear text), ${ }^{200}$ the size of the screen, ${ }^{201}$ and the detachment of the text from the "physical dimension",202 have all been studied for how they impact the reader experience of the on-screen text.

With respect to long-form text, that is, the kind of text that is expected to be read linearly, like a book, one study of readers showed the iPad measured a $6.2 \%$ lower reading speed than print while the Kindle was $10.7 \%$ slower. $^{203}$ Another study showed, however, that fifty-two percent of iPad users said it was easier to read the screen than the printed page. ${ }^{204}$ Differences have also been reported based on the variations in screen size; a recent study showed that reading comprehension from an iPhone sized screen for complex web content was only forty-eight percent of the comprehension on desktop monitors. ${ }^{205}$

Reading on-screen generally involves more browsing, scanning, and reading selectively and threatens what experts call "sustained" reading, ${ }^{206}$ reading in a focused, in-depth, and attentive manner. This problem is exacerbated by hypertext presentation of the material on screen. That is, because hypertext is often nonsequential, discontinuous, and nonlinear, it discourages sustained reading and

only is our screen reading distinctly different from print reading, but our reading modes and habits in general are changing due to steadily increasing exposure to digital texts.").

200 See, e.g., Ziming Liu, Reading Behavior in the Digital Environment: Changes in Reading Behavior Over the Past Ten Years, 61 J. Documentation 700, 707 (2005) (discussing hypertext and linear on-screen reading difficulties).

201 Jakob Nielsen, Mobile Content is Twice as Difficult, NNGRoup.COM (Feb. 28, 2011) [hereinafter Nielsen, Mobile Content], http://www.nngroup.com/articles/mobile -content-is-twice-as-difficult (noting that reading complex web content from an iPhonesized screen significantly decreased comprehension scores); Jakob Nielson, iPad and Kindle Reading Speeds, NNGROUP.COM (July 2, 2010) [hereinafter Nielsen, iPad and Kindle], http://www.nngroup.com/articles/ipad-and-kindle-reading-speeds/ (looking at the differences between reading "long form text" on computer screens, iPads, and Kindles).

202 See Mangen, supra note 199 (describing the "haptic" issues of reading from a screen).

203 See Nielsen, iPad and Kindle, supra note 201, at 3 (noting that there was not a statistically significant difference between the iPad and Kindle).

204 Press Release, Gartner, Inc., Gartner Survey Shows Digital Text Consumption Nearly Equal to Time Spent Reading Printed Paper Text (May 10, 2011), http://www.gartner.com/newsroom/id/1673714.

205 See Nielsen, Mobile Content, supra note 201, at 2.

206 Liu, supra note 200, at 701. 
reading in an "absorbed and reflective" mode. ${ }^{207}$ But, even with webpage reading, the same studies note that webpage readers will read more in-depth when they seek specific information. ${ }^{208}$

"Scrolling" through a text presents a problem with "linear" onscreen reading. With print reading, readers "flip" and "scan" to get a sense of the information in a document; scrolling does not allow for this kind of information control and thus can affect comprehension and speed. ${ }^{209}$ Studies show that scrolling through a document requires more mental energy and can impact attention and working memory. $^{210}$

Attitude may be another factor that impacts on-screen reading. For example, on-screen readers may take their reading less seriously than reading "print on paper." One study, for example, showed that individuals who read on-screen tend to take shortcuts and spend "more time browsing, scanning, and hunting for keywords compared with people reading on paper." 211 Moreover, the time pressure that a reader feels may create differences between paper and on-screen comprehension. In one study, where paper and on-screen readers had a time-pressured test to complete, both groups performed equally well on the test. ${ }^{212}$ But, when the groups had extended time to read the text, the paper group did better than the on-screen group. ${ }^{213}$ This suggests that the print group may have been able to engage in more self-regulation of learning strategies than the on-screen group. ${ }^{214}$

These difficulties with on-screen reading may result from the way readers tend to perceive text structure. According to recent research, readers perceive text as a "physical landscape"; that is, readers "construct a mental representation of the text in which meaning is anchored to structure." $" 15$ Often, the context features of a paper text

\footnotetext{
207 Id. at 707.

$208 \mathrm{Id}$. at 706.

209 Id. at 703.

210 Ferris Jabr, The Reading Brain in the Digital Age: The Science of Paper Versus Screens, SCI. AM. (Apr. 11, 2013), http://www.scientificamerican.com/article.cfm?id =reading-paper-screens (discussing studies).

211 Id. (citing Liu, supra note 200).

212 Id. (describing the study documented in Rakefet Ackerman \& Morris Goldsmith, Metacognitive Regulation of Text Learning: On Screen Versus on Paper, $17 \mathrm{~J}$. EXPERIMENTAL PSYCHOL. 18 (2011)).

213 Id.

214 Id.

215 Id.
} 
are missing from the on-screen reading environment. ${ }^{216}$ As a result, readers have a more difficult time "mapping" the "journey" through the text, which is linked to decreased speed and comprehension. ${ }^{217}$ One usability expert noted the loss of context that comes from reading from a screen could result in remembering less of the content-the smaller the screen, the worse the result. ${ }^{218}$ Consequently, designers have worked to make "an e-reader or tablet as close to reading on paper as possible.",219

For the purposes of considering objective memos in legal writing, the literature suggests that one of the most significant issues with onscreen reading is likely the reader's lack of context for the content that often comes with the paper text. The absence of this context makes it more difficult for the reader to make a mental map of the text. This inability to effectively "map the screen" may affect reader comprehension and speed, particularly where a document is longer and requires scrolling and the screen is smaller, allowing less text to appear on the screen at any one time. In addition, it is possible that legal readers may be less self-regulated when reading on-screen. They may be tempted to skim and browse the on-screen legal memo to the detriment of their comprehension.

These two concerns suggest that legal writers need not abandon indepth, careful, competent writing if that writing is to be read onscreen. ${ }^{220}$ Rather, it suggests that writers must pay particular attention to structuring the text of a memo so that an on-screen reader can easily navigate the document. Recognizable structural cues that are common to the traditional memo, then, might make a significant

$216 I d$. Things like being able to feel the thickness of the pages, the ability to turn the pages, and the ability to focus on one page while having a sense of the entire text are all things available in a "print on paper" text that are difficult to replicate on the screen. See Mangen, supra note 199, at 408.

217 Jabr, supra note 210.

218 "The most dramatic example is reading from mobile phones. [You] lose almost all context." Maia Szalavitz, Do E-Books Make it Harder to Remember What You Just Read?, TiME.COM (Mar. 14, 2012) (quoting Jakob Nielson), http://healthland.time.com/2012/03 /14/do-e-books-impair-memory.

219 Jabr, supra note 210.

220 In the context of describing short and long-form writing for the web, Jakob Nielsen suggests the following: "If you [are writing for people] who really need a solution, focus on comprehensive coverage. This is a good strategy if you sell highly targeted solutions to complicated problems." Jakob Nielsen, Long vs. Short Articles as Content Strategy, NiELSEN NORMAN GROUP (Nov. 12, 2007), http://www.nngroup.com/articles/content -strategy-long-vs-short. This description could not be more apt for legal writers writing legal memos. 
difference to the on-screen reader's speed and cognition, particularly for those reading on a mobile device. Moreover, having an overt and recognizable text structure might encourage a legal reader to think more reflectively and deeply about the text and may encourage comprehension, speed, and memory. All of this suggests that onscreen legal memoranda benefit, as do print memoranda, from the knowledgeable use of "text structures," and the next section turns to that topic.

\section{Text Structure and the Objective Memo}

The literature about text structures suggests that identifying and using text structures is critical to reader comprehension. For on-screen reading, the text structure of an objective memo is a navigational tool that assists readers in understanding the information. Thus, instead of focusing on the differences between "e-mail" memos, "informal" memos, and "comprehensive" memos, writers should be focusing on techniques that encourage on-screen readers to read memos in-depth, attentively and reflectively, and with speed and comprehension. This section first gives an overview of text structures, then explains the link between text structures and the objective memo, and finishes by addressing effective text structures for on-screen reading.

\section{a. Overview of Text Structures}

"Text structure" refers to the way text is organized within a particular piece of writing. ${ }^{221}$ This structure can be implemented at the paragraph level or larger. ${ }^{222}$ Readers comprehend texts most easily when those texts are well-structured and that structure can be identified. ${ }^{223}$ For professional readers, like lawyers, text structure is critical for information retention whether or not the information is interesting or uninteresting to the reader. ${ }^{224}$

221 Using Text Structure, NAT'L EDUC. ASs'N, http://www.nea.org/tools/using-text -structure.html (last updated Sept. 13, 2013).

222 Karin K. Hess, Teaching and Assessing Understanding of Text Structures Across Grades, NAT'L CENTER FOR THE IMPROVEMENT OF EDUC. ASSESSMENT (2008), www.nciea.org/publication_PDFs/TextStructures_KH08.pdf.

223 David Charney, The Effect of Hypertext on Processes of Reading and Writing, in LiterACY: A CRITICAL SOURCEBOOK 85 (Ellen Cushman et al. eds., 2001); Hess, supra note 222 , at 1 (noting that "[e]xplicit text structure facilitates reading comprehension").

224 See Wilbert Spooren et al., The Role of Interest and Text Structure in Professional Reading, 21 J. RES. READING 109, 109 (1998). 
Text structures are particularly important because, "as people read, they build a hierarchically structured mental representation of the information in the text." 225 Readers find it "more difficult to create a mental representation of a disjointed or disorganized text."226 The more organized a text, that is, the more carefully sequenced and connected it is, the easier it is for a reader to understand a text. ${ }^{227}$ "Studies of reading comprehension confirm that readers understand and learn most easily from texts with well-defined structures that clearly signal shifts between parts." 228 In fact, "the easiest texts to read are those based upon a familiar structural pattern or genre."229

Since a reader "cannot think about everything at once," text structures make it easier to construct a coherent representation of a text by allowing the reader to "focus on a few things at a time in some order." 230 The ability of the reader to mentally structure the text "crucially depend[s] on the order in which readers encounter the propositions and on the amount of repetition and development of important concepts (or arguments) in successive portions of the text." 231 Moreover, the "sequence of sentences and sections of a text and the explicitness of their connection to one another largely determine how well and how easily a reader can construct a text base." 232 Text structures give "form" to the text and assist readers with text navigation, critical reading, and comprehension by allowing readers to engage with a "highly organized text format" that is more effective than an "amorphous network" in enabling the reader to make the "specific set of associations" the writer intends. ${ }^{233}$

There are a multitude of text structures, from "small units, such as sentences and paragraphs, all the way to grand structures that describe entire texts, such as sonnets, fairy tales, resumes, or policy arguments. Indeed, readers depend on such patterns to identify a text's genre, anticipate its development, and integrate its parts.",234

225 Charney, supra note 223 , at 89.

$226 \mathrm{Id}$. at 90 . In fact, studies have shown that texts presented in a linear structure facilitated memory, information retention, and mental effort as opposed to information presented in a "hypertext" structure. Id. at 97.

227 Id. at 90.

228 Id. at 85.

229 Id. at 91 .

$230 I d$. at 89 .

$231 \mathrm{Id}$. at 90

232 Id

$233 \mathrm{Id}$. at 89 .

$234 \mathrm{Id}$. at 85. 
Texts can be structured at the paragraph level or at a larger level appropriate for the genre or purpose of the text. ${ }^{235}$ Some text structures operate at the "macro" level and relate the way in which the ideas in the text are presented. For example, some text structures present information by sequence, chronology, description, definition, or comparison-contrast. ${ }^{236}$ At an even more complex level, information can be presented in patterns that include problemsolution, cause-effect, proposition-support, judgment-critique, and induction-deduction. ${ }^{237}$ Expository texts-nonfiction texts that convey information ${ }^{238}$ - typically include multiple organizational patterns. ${ }^{239}$ These patterns sometimes include the narrative patterns associated with fiction texts. ${ }^{240}$

At a more "micro level," text structures can include "informative titles, headings, overviews, and topics sentences [that] introduce[e] key concepts that are repeated and developed in successive portions of text." ${ }^{241}$ Associated with "micro level" text structures are "text pattern signals," which are words and phrases embedded in the text to signal the text structure. ${ }^{242}$ An example of a "text pattern signal" is "if ... then" to indicate a cause and effect structure. ${ }^{243}$ Even bullets, diagrams, outlines, and bold text can be text pattern signals. ${ }^{244}$

\section{b. Text Structures and the Objective Memo}

The objective memo is a well-recognized text structure that can facilitate reader navigation, critical reading, and comprehension. Arguably, that structure combined with other easily recognizable text structures is even more important than ever for on-screen reading because on-screen reading may result in decreased comprehension

\footnotetext{
235 Hess, supra note 222, at 1.

236 Id. at 2.

237 Id.

238 RaChel L. McCormack \& Susan Lee Pasquarelli, Teaching Reading: STRATEGIES AND RESOURCES FOR GRADES K-6, at 133 (2010).

239 Kendra M. Hall et al., Expository Text Comprehension: Helping Primary-Grade Teachers Use Expository Texts to Full Advantage, 26 REAdING PSYCHOL. 211, 212 (2005).

240 MCCORMACK \& PASQUARELLI, supra note 238, at 133.

241 Charney, supra note 223, at 91.

242 Hess, supra note 222, at 3. Legal writers would recognize many of these signals as transitional phrases.

${ }^{243} I d$.

244 Id. at 4.
} 
simply as a result of the medium. Signaling to the reader that the memo includes the traditional parts of the legal memorandum, such as a question presented, can help the reader more quickly identify the structure of the text and determine what information is important.

The discussion section of a legal memorandum is itself a complex form of expository writing that contains a myriad of text structures. Because legal memo writing is rule-based writing, ${ }^{245}$ it typically has a well-defined internal structure that is built around a legal rule. Other commentators have recognized that because of its rule-based nature, the legal memo for electronic reading should be "constructed to flow in a logical sequence." 246

In addition, the objective memo as a whole contains numerous text structures. Take, for example, a basic writing problem where a lawyer is asked to analyze a legal issue and predict the outcome. The overall structure of this memo would be a problem-solution structure. The writer should first set out the problem in the question presented or issue section, and then to offer the solution, first in a brief answer, and then in detail in the discussion section.

In the statement of facts and discussion sections, however, other text structures will be used to flesh out the problem and solution. Setting out the statement of facts will most typically require a chronological organizational pattern. Then, in the discussion section, the lawyer might use a proposition-support structure, first proposing to the reader what the predicted outcome of the legal issue might be. To build the legal rule, the writer will articulate the rule by using, perhaps, a deductive description combined with definition. To describe the cases in support of the rule, the writer will use description, coupled with induction. In the analysis, where the lawyer will apply the law to the facts, comparison-contrast will be appropriate. Overall, the memo is a form of judgment and critique, where the lawyer is setting out a series of criteria by which the facts of the case are judged.

The multitudes of text structures emb0edded within a legal memo demonstrate that a memo is "formal" to the extent that it is based on the conventions of the legal domain; that is, it cannot be "informal" in

245 Karen L. Koch, A Multidisciplinary Comparison of Rules-Driving Writing: Similarities in Legal Writing, Biology Research Articles, and Computer Programming, 55 J. LEGAL EDUC. 234, 238 (2005) (noting that in legal writing, "various rules strictly control each part of the writing process ... [, which] starts with the rule[s] before going into examples, description, or analysis").

246 DuVivier, supra note 5, at 70. 
that it lacks form or structure. Accordingly, "formality" is not something to be avoided as a result of new technology; rather, it is a resource that originates from that nature of legal analysis itself. In the legal memo-writing context, the idea of formality simply means the resources by which the symbols of reasoning are arranged within a given text, or, in other words, its text structure. ${ }^{247}$

Moreover, the complexity of the objective memo text demands that the writer recognize the multitude of text structures within the document, so the writer successfully can assist the reader in navigating through them. ${ }^{248}$ The goal of the legal memorandum is to guide the reader, step-by-step through the analysis, and make the associations between facts and law the writer seeks to convey. Accordingly, a highly organized text format, where the facts, law, and analysis are clearly set forth, is most likely to achieve that goal.

Legal memo writers should have the goal of enabling a legal memo reader to experience the document in a sequential, continuous, linear progression because comprehension will increase as a result. Moreover, given that reading on the screen means, perhaps, scrolling or shifting from screen to screen, writers should use effective navigational structures to help readers navigate memos on the screen and ease their cognitive load when scrolling or shifting is required. In other words, instead of using less form to assist legal readers, they should use more, perhaps even more so than when writing for "onpaper" reading. Even if readers might use the document in a nonlinear way, ${ }^{249}$ the structures the writer uses will assist those readers in effectively navigating the document and moving to the information the reader finds most important.

\footnotetext{
247 See BURKE, supra note 98 (discussing "form" as a resource, which suggests that text structures are resources for legal writing).

248 Charney, supra note 223, at 89; see also Maria Perez Crist, The E-Brief: Legal Writing for an Online World, 33 N.M. L. REV. 49, 75 (2003) (directing writers of online documents to "share your navigational plan with the reader").

249 Some argue that it is "idealistic" to think that legal documents are read linearly. See Don Cruse, Study Compares Reading on E-Readers, Monitors, and Paper, SUP. CT. OF TEX. BLOG (July 6, 2010), http://www.scotxblog.com/legal-tech/electronic-briefs/study compares-reading-experiences-of-e-readers-monitors-and-paper/ ("Although we write briefs to have a narrative flow, they quickly become a random-access medium. Judges and law clerks need to locate the relevant discussion of a particular issue, case, or piece of evidence.”).
} 


\section{c. Effective Text Structures for On-Screen Reading}

What structural features should lawyers consider when writing legal memoranda for reading on the screen? For most legal writers, these suggestions will serve as a reminder of the fundamental and traditional techniques of legal writing.

To start, writers should follow the same structure as readers have come to expect from objective memos, within the flexibility that comprehensiveness allows. Because "past reading experience is the key to good critical reading," 250 legal readers are more likely to be more successful readers when encountering a legal memo form that they recognize. Thus, legal writers should start with the notion that a comprehensive memo-one that typically contains a question presented, brief answer, facts, discussion, and conclusion-is needed. If the type of question asked of the writer is less complex, then this comprehensive form can be modified, but only to the extent that it is still recognizable to the reader. Using the traditional parts of the objective memo serves to enhance cognition and navigation for readers, thereby freeing cognitive energy to examine the text for its deliberative qualities; thus, a formal structure for the memo can serve as a "forcing function" for both writer and reader that facilitates deliberation and places a check on intuition and biases.

With respect to internal text structures, a memo must carefully set out the law and the analysis of the facts in light of the law. If a different kind of analysis is called for, for example, an analysis of competing legal authorities, that analysis must be carefully set out as well. The steps of the analysis must be complete. ${ }^{251}$ There should be no shortcuts in describing the facts and the reasoning. Counteranalysis that fulfills the duty to doubt must be included. And, all of this must follow the typical text structure for "objective" legal

250 Debra Moss Curtis \& Judith R. Karp, In a Case, On the Screen, Do They Remember What They've Seen? Critical Electronic Reading in the Law School Classroom, 30 HAMLINE L. REV. 247, 275 (2007). See also Robert B. Dubose, Legal Writing for the ReWired Brain: How to Communicate in a Paperless World, in STATE BAR OF TEX. ANN. Meeting Law Prac. Mgmt. ClE Materials 17 (June 11, 2010), available at $\mathrm{http} / /$ www.texasbar.com/flashdrive/materials/managing_your_law_practice/Special _ManagingYourLawPracticeCLE_LegalWritingRewiredBrain_Dubose_FinalArticle.pdf (encouraging legal writers for the screen to "[s]atisfy the reader's expectations by following the conventions" of the office memo and include "the issue, the short answer, and the discussion").

251 DuBose, supra note 250, at 16 ("Legal writers should never omit any step in their arguments."). 
reasoning; a discussion of the law followed by application of the law to the facts, followed by counteranalysis.

Navigational structures and signals that guide the reader through the text should be used as well. Thesis sentences, roadmap paragraphs, and headings can help a reader, particularly an on-screen one, navigate more easily through the document and see the logical connections between ideas in the text. ${ }^{252}$ Moreover, the headings can give the reader context within the document, particularly when that document needs to be "scrolled" through in order to be read, and it can help the reader find the information of interest, which will allow her to read the information more deeply and reflectively. ${ }^{253}$ Certainly, memos conveyed in the body of an e-mail, for example, would benefit greatly from the generous use of headings.

In addition, now that many documents, including PDF documents, have a "document map" or table of contents on the screen at all times, headings provide even more structure for a document on-screen than they did on paper because those clickable headings allow easier navigation throughout the document. These navigational structures also permit a reader to skim a document, a prereading process that is a critical part of professional reading. ${ }^{254}$

Finally, online writers should pay extra attention to the use of boldface type and bullet points for emphasis of important points, to text structure signals that show the relationship between ideas, and in using well-constructed, concise paragraphs to aid the reader who might be using a small screen. ${ }^{255}$

\section{CONCLUSION}

AlBus DUMBLEDORE. (Looking into a large stone bowl filled with glowing, white liquid.) I use the Pensieve. One simply siphons the excess thoughts from one's mind, pours them into the basin, and

$252 \mathrm{Id}$. at 14 (advocating the use of headings, short summaries, and topic sentences for online legal writing).

253 Id. at 13-14 (advocating writing strategies that "enable skimming").

254 "Critical reading starts with pre-reading techniques: an awareness of purpose followed by a preview of the material gained by looking over titles, headings, subheadings, graphics italic and bold print - all before beginning to read. Readers then skim the passage before reading it and begin reading having answered the questions of 'what is the main idea,' 'what kind of writing is it,' and 'what is the author's purpose.'” Curtis \& Karp, supra note 250, at 278-79.

255 See Crist, supra note 248, at 76 (discussing the use of short paragraphs for on-screen writing). 
examines them at one's leisure. It becomes easier to spot patterns and links, you understand, when they are in this form.

HARRY POTTER. You mean ... that stuff's your thoughts?

Albus Dumbledore. Certainly.

$$
\text { - Harry Potter and the Goblet of Fire }{ }^{256}
$$

Until the creation of a legal pensieve, an objective memo remains the best tool for a legal writer or reader to objectively examine legal thoughts and identify patterns and links essential for competent advice giving. Critics of the traditional objective memorandum in the mobile reader context are too quick to dismiss the importance of writing the analytical objective memo to deliberative decision making for both writer and reader. For the writer, writing acts as a pensieve, creating a space for deliberation and dialectic that underlies reasoned judgment. And for readers, engagement with the written text creates a similar space for deliberation and reasoning.

The legal memorandum is important as a heuristic device for writing. If one sees a memo as merely restating what can be "found" in the law and what can be logically deduced from what has been found, then it is easy to see how the memo, in its comprehensive form, may be unnecessary. But, as Joel Cornwell notes, a memo is not simply an "algorithmic exercise"; ${ }^{257}$ rather, memos are a place to be "creative and educative," and are the product of writers who "use language ... to reach new formulations of the positions" and perpetually remake the law. ${ }^{258}$ The memo, no matter its technological medium, is essential to competent lawyering. The memo's formalism forces well-developed deliberation that leads to creative problemsolving and advice giving. It provides a rhetorical "space between" for knowledge construction; the memo itself is the construction of legal advice, not just the recording of it.

Criticisms of writing the traditional memo for on-screen reading also miss the importance of the legal memo to the reader. First, the comprehensive "form" of a memo ensures that readers get what they need to exercise their own interpretations and judgment of the text. Accordingly, readers should embrace the traditional memorandum

256 Pensieve, HARRY POTTER WIKI, http://harrypotter.wikia.com/wiki/Pensieve (last visited Nov. 18, 2013).

257 Joel R. Cornwell, Legal Writing as a Kind of Philosophy, 48 MERCER L. REV. 1091, 1119 (1997).

258 Imagining the Law, supra note 79, at 35. 
and text structure as a means to facilitate deliberative decision making and advice giving. Second, pitting "formal" against "informal" and "traditional" against "non-traditional" in memo writing misdirects the argument about how to write and read legal memos in a new medium. Instead of structuring the discussion around these false dichotomies, writers and readers should both consider what is necessary for a competent memo in any rhetorical situation.

Moreover, in thinking about the memorandum for on-line reading, it is important not to conflate the medium for reading legal memos with the essential nature of the message. Electronic reading and transmission of objective memos are simply additional developments in the technology of writing and reading. The core advice-giving function of the memo, however, has not changed. So, instead of trying to change the memo to meet the needs of technology, the goal should be to adjust the use of the medium to meet the needs of the domainspecific writing and reading that legal practice requires. As Walter Ong notes, "all states of the word-oral, chirographic, typographic, electronic-impose their own confusions, which cannot be radically eliminated but only controlled by reflection." 259 Accordingly, our job is to reflect on how those confusions can be controlled, through the use of text structures that assist readers.

Finally, the limits placed upon the memo when conveyed electronically are misplaced. One cannot overlook that reading onscreen will persist well into the future and may become the dominant mode of reading. Moreover, it cannot be denied that the types of screens upon which reading takes place will continue to change in size and shape, perhaps in ways we cannot yet imagine. Thus, rather than suggest that only certain types or lengths of objective memos are suitable for on-screen reading via e-mail or otherwise, writers should implement strategies and text structures that make memos more understandable to the reader on any screen. In other words, the medium should not dictate a change to the objective memo that yields less-than-competent results. The medium should serve the message. New technologies should not deter a lawyer from writing-or reading - a memo necessary to convey competent legal analysis, regardless of how it will be read.

As always, naming plays an important role in the development of ideas. To adapt the legal memo to new technological mediums, new

259 Ong, supra note 14 , at 30. 
terminology has developed - the "substantive e-mail" and the "informal" memo. In this author's opinion, this terminology should be dropped from the lexicon. Instead, the objective memo should remain the "objective memo," and the term should encompass all lawyer-tolawyer communication, on any medium, that is designed to provide the analytical basis for legal advice giving. Instead of focusing on creating new categories of legal documents, the discourse about the objective memo should focus on flexibility and competency in all memo writing, technologically mediated or otherwise, recognizing that although each rhetorical situation is different, competence is always required.

The traditional memo is not dead. In fact, in the technological, fastpaced society that legal practice replicates, it deserves to be revived fully to facilitate deliberative decision making and reduce the risks that come with efficiency, bias, and intuitive decision making. In a mobile computing world, lawyers are invited to "blink." On-screen objective memos should encourage legal readers to "stare"- to study and reflect upon what has been written and to give sound legal advice. Writing and reading objective memoranda for computer mediated communication requires focusing more than ever on the traditional structures of legal writing and a commitment to competence. 